\title{
WestVirginiaUniversity
}

THE RESEARCH REPOSITORY @ WVU

Graduate Theses, Dissertations, and Problem Reports

2021

\section{Exposure Therapy: Stimulus Intensity as a Factor in Treatment Preference}

\author{
Matthew C. Arias \\ mcarias@mix.wvu.edu
}

Follow this and additional works at: https://researchrepository.wvu.edu/etd

Part of the Cognition and Perception Commons

\section{Recommended Citation}

Arias, Matthew C., "Exposure Therapy: Stimulus Intensity as a Factor in Treatment Preference" (2021). Graduate Theses, Dissertations, and Problem Reports. 7749.

https://researchrepository.wvu.edu/etd/7749

This Dissertation is protected by copyright and/or related rights. It has been brought to you by the The Research Repository @ WVU with permission from the rights-holder(s). You are free to use this Dissertation in any way that is permitted by the copyright and related rights legislation that applies to your use. For other uses you must obtain permission from the rights-holder(s) directly, unless additional rights are indicated by a Creative Commons license in the record and/ or on the work itself. This Dissertation has been accepted for inclusion in WVU Graduate Theses, Dissertations, and Problem Reports collection by an authorized administrator of The Research Repository @ WVU.

For more information, please contact researchrepository@mail.wvu.edu. 
Graduate Theses, Dissertations, and Problem Reports

2021

Exposure Therapy: Stimulus Intensity as a Factor in Treatment Preference

Matthew C. Arias

Follow this and additional works at: https://researchrepository.wvu.edu/etd

Part of the Cognition and Perception Commons 
Exposure Therapy: Stimulus Intensity as a Factor in Treatment Preference

Matthew C. Arias, M.S.

A dissertation submitted to the Eberly College of Arts and Sciences at West Virginia University in partial fulfillment of the requirements for the degree of Doctor of Philosophy in Psychology

Daniel W. McNeil, Ph.D., Chair

Aaron Metzger, Ph.D.

Shari Steinman, Ph.D.

Robert Stuchell, D.M.D.

Constance Toffle, Ph.D.

Department of Psychology

Morgantown, West Virginia

2020

Keywords: exposure, specific phobia, dental fear, treatment preferences Copyright 2020 Matthew C. Arias 


\begin{abstract}
Exposure Therapy: Stimulus Intensity as a Factor in Treatment Preference
\end{abstract}

Matthew C. Arias

Currently, a host of treatments are available for treating anxiety disorders, including specific phobia. Treatment of specific phobia includes pharmacological, psychosocial, and combined approaches. Exposure therapy, however, is considered the leading psychological treatment for specific phobia, and has shown to be effective. Exposure therapy challenges held beliefs about feared stimuli/situations and attempts to integrate new learning about the feared object/situation. Despite exposure being effective to treat specific phobia, it is associated with low adherence and high dropout rates. There is a need to examine, therefore, ways to improve patient adherence for exposure. A way to examine this issue is to assess patient preferences for currently available treatments for specific phobia, and to examine directly the various methods for delivering exposure (e.g., stimuli intensity presentation). Furthermore, it is important to assess individuals' perception of efficacy on various methods of delivering exposure stimuli (e.g., low intensity versus high intensity). Also, it is essential to examine individual willingness to engage in different presentation of stimuli intensity. Participants $(N=1,065)$ were assessed for dental carerelated fear and anxiety, and 279 of those individuals with high levels of fear/anxiety were included in the analyses regarding treatment preferences. Participants rated their preference for types of treatments (e.g., exposure, flooding, systematic desensitization) and were asked to rank order-based on personal preference. Then participants watched two video examples of exposure (i.e., low intensity and high intensity) and asked to rate their preference for the two methods to deliver exposure stimuli. After, participants rank ordered several approaches for delivering exposure stimuli by personal preference. Finally, participants were given a free choice to watch either a black screen (e.g., avoidance), low intensity exposure video, or high intensity exposure video over three trials. Results indicated that participants rated relaxation as the most preferred type of treatment for dental phobia. In regard to exposure stimuli, participants rated the low intensity exposure stimuli with greater preference (e.g., more efficacious and more willing to engage in the treatment) than the high intensity exposure stimuli. A majority of participants watched the low intensity (39.6\%) and the avoidance video (32.8\%) two or more times over the three trials demonstrating a behavioral preference for video content. A Latent Class Analysis suggested distinct groups (i.e., Low to Avoidant, and Avoidant) based on the patterns of video choice over the three trials. Findings of this study highlight differences in patient preferences for specific phobia treatment, which ultimately can impact oral health care services and training. Utilizing low intensity exposure stimuli may be a promising way to get patient buy-in and ease into higher intensity stimuli and possible improve treatment outcomes. 


\section{Table of Contents}

Acknowledgements $\quad$ iii

Introduction 1

Specific Phobia 2

Psychosocial Treatments for Specific Phobia $\quad 2$

Cognitive behavior therapy (CBT) 2

Exposure therapy 3

$\begin{array}{ll}\text { Pharmacological Treatments for Specific Phobia } & 6\end{array}$

$\begin{array}{ll}\text { Benzodiazepines } & 7\end{array}$

Selective Serotonin Reuptake Inhibitors (SSRI) $\quad 7$

$\begin{array}{ll}\text { Beta-blockers } & 7\end{array}$

$\begin{array}{lr}\text { Sedatives } & 8\end{array}$

Patient Adherence for Specific Phobia Treatments 9

$\begin{array}{ll}\text { Patient Preferences for Type of Treatment } & 10\end{array}$

Medication versus psychotherapeutic treatment 11

CBT versus other psychotherapeutic treatments $\quad 12$

Increasing Willingness to Engage in Exposure Treatment 12

$\begin{array}{ll}\text { Statement of the Problem } & 14\end{array}$

$\begin{array}{ll}\text { Hypotheses } & 15\end{array}$

$\begin{array}{ll}\text { Method } & 16\end{array}$

$\begin{array}{ll}\text { Participants } & 16\end{array}$

$\begin{array}{ll}\text { Video Stimuli } & 18\end{array}$

$\begin{array}{ll}\text { Descriptions of Treatment Options } & 19\end{array}$

$\begin{array}{ll}\text { Self-Report Measures } & 19\end{array}$

Demographic and general dental information questionnaire 19

$\begin{array}{ll}\text { Dental Fear Survey (DFS) } & 19\end{array}$

Preference, treatment effectiveness, and willingness to engage in treatment 20

$\begin{array}{ll}\text { Validity checks } & 21\end{array}$ 
$\begin{array}{ll}\text { Behavioral Preference Measure } & 21\end{array}$

$\begin{array}{ll}\text { Procedure } & 21\end{array}$

$\begin{array}{ll}\text { Screening Phase } & 21\end{array}$

Preference Phase $\quad 22$

$\begin{array}{ll}\text { Study Analyses } & 22\end{array}$

$\begin{array}{ll}\text { Results } & 23\end{array}$

$\begin{array}{ll}\text { Hypothesis } 1 & 23\end{array}$

$\begin{array}{ll}\text { Hypothesis } 2 & 24\end{array}$

$\begin{array}{ll}\text { Hypothesis } 3 & 25\end{array}$

$\begin{array}{ll}\text { Discussion } & 27\end{array}$

References $\quad 33$

$\begin{array}{ll}\text { Figures } & 46\end{array}$

$\begin{array}{ll}\text { Tables } & 50\end{array}$

$\begin{array}{ll}\text { Appendices } & 53\end{array}$ 


\section{Acknowledgements}

First and foremost, I am thankful for the time and guidance offered to me by the members of my thesis committee, Daniel McNeil, Aaron Metzger, Bob Stuchell, and Constance Toffle. Dan was particularly helpful with his direct guidance and feedback of this project. In addition to serving as my committee chair, Dan allowed me to conduct meaningful research and was always supportive of me. Gratitude should be given to members of the Anxiety, Psychophysiology, and Pain Research Laboratory, Casey Wright and Cecelia Nelson. I am appreciative of all the help they provided throughout this project. Lastly, I want to thank all of my family for their support. In particular, I thank my wife, Nicole, for her understanding and patience during this timeconsuming project. 
Exposure Therapy: Stimulus Intensity as a Factor in Treatment Preference A myriad of treatments are available for treating anxiety disorders, including specific phobia. Psychotherapy for the treatment of specific phobia ranges from developing alternative, positive thoughts about the feared stimulus/situation, to uncovering unconscious processes that contribute to the experience of anxiety, to experiencing situations in which fearful responding is challenged with new learning. Despite the availability of various treatments for phobia, less than $50 \%$ of affected people utilize any available treatment for this disorder (Wang et al., 2005). Exposure therapy, a specific Cognitive Behavior Therapy (CBT) method, has been shown to be efficacious and is considered a leading treatment for specific phobia; however, it often has low utilization rates (Choy, Fyer, \& Lipsit, 2007; Daflos \& Whittal, 2012; Wolitzky-Taylor, Horowitz, Powers, \& Telch, 2008). Moreover, dropout is common with exposure, and has rates as high as $45 \%$ for specific phobia treatment (Choy et al., 2007). Exposure treatment may be perceived and experienced as particularly challenging difficult by patients because the goal is to change fear responding by purposely contacting fear-evoking stimuli and situations.

Given the issues of low utilization and high dropout, there is a need to examine what patients prefer and will tolerate in the treatment of phobia involving exposure. One salient factor related to patient preference in exposure treatment is the level of stimulus intensity. For example, actually flying on an airplane would be a high intensity step for someone with a phobia of flying. In this case, a contrasting low intensity exposure would be sitting in an airport, without a planned airline trip. Successfully boarding and flying on a plane would be an end goal for someone with a phobia of flying, and would be an ideal exposure situation, but few patients would prefer or tolerate that step early in treatment. There are one-session exposure treatments for specific phobias (Davis, Ollendick, \& Ost, 2012), but they are daunting for many patients. 
Patient preference is believed to relate to patient adherence, defined as "the ability of an individual to conform to a treatment regimen... as outlined by a health care provider" (American Psychological Association, 2015, p. 21). Adherence in relation to psychotherapy at least involves a patient attending psychotherapy sessions, active engagement in those treatment sessions, and completing out-of-session homework assignments. The importance of this issue is that even the most effective treatments must be accepted and utilized by patients for positive outcomes to occur (McNeil, 2011).

\section{Specific Phobia}

Specific phobia is one of the anxiety disorders as defined by the Diagnostic and Statistical Manual of Mental Disorders, $5^{\text {th }}$ edition (DSM-5), and is the experience of fear related to a particular stimulus/situation, worry related to encountering the feared object/situation, and hindrance of daily functioning (American Psychiatric Association, 2013). The DSM-5 has five category types of specific phobia: Animal, Natural Environment, Situational, Blood/Injection/Injury, and Other. Prevalence rate for specific phobia is $8.7 \%$, and over $20 \%$ of those with a specific phobia are considered in the severe category (Kessler et al., 2005). This study involved individuals with high levels of dental care-related fear/anxiety as an exemplar for specific phobia (McNeil \& Randall, 2014) due to high prevalence rates (e.g., up to 20\%) in the USA and similar avoidant behaviors as observed in other phobias (Smith \& Heaton, 2003).

\section{Psychosocial Treatments for Specific Phobia}

Cognitive behavior therapy (CBT). CBT is a common and effective approach for treating phobia and other disorders, and incorporates behavioral (e.g., extinction) and cognitive (e.g., thought restructuring) principles. CBT can include many different techniques to help treat specific phobia, such systematic desensitization, exposure, or flooding (O’Donohue \& Fisher, 
2009). Other CBT approaches include thought restructuring (i.e., disputing negative thoughts about a feared object/situation by examining the evidence) and arousal control (e.g., activating the parasympathetic nervous system through relaxation, diaphragmatic breathing, and/or progressive muscle relaxation when encountering feared stimuli).

Exposure therapy. Several forms of exposure therapy exist, such as in vivo (e.g., reallife), in vitro (e.g., role-play), and in imago (e.g., imaginal); see McNeil and Kyle (2017). Additionally, exposure itself is the basis for systematic desensitization, flooding, and implosive therapy, although "exposure" has become known as its own method (McNeil \& Kyle, 2017). Systematic desensitization was the first rendition of exposure therapy, developed by Wolpe (1958), used in combination with relaxation training or medication, and based on classical conditioning principles. Specifically, systematic desensitization was first based on the theory of counterconditioning (e.g., maladaptive associations being replaced with adaptive ones by pairing the fear with something positive; Masters, Burish, Hollon, \& Rimm, 1987). Since two incompatible responses cannot exist simultaneously, systematic desensitization typically utilizes relaxation training as an incompatible response to anxiety/fear (Masters et al., 1987). Once the patient is trained in relaxation, then a fear hierarchy is constructed, which is a list and/or description (typically consisting of $10-15$ items) of fear/anxiety-evoking situations (Masters et al., 1987). Typically, the hierarchy increases in intensity, first with early "easy” steps followed by higher intensity ones over the series, culminating in the goal response (e.g., having a dental treatment visit for someone with dental phobia; McNeil \& Kyle, 2017). The patient works through the fear hierarchy with the therapist by starting at the first step and practicing relaxation during imaginal exposure, and then only moves onto the next step when the fear response is no 
longer experienced, or is sufficiently reduced, during the current step (Masters et al., 1987).

Overall, the process is designed to limit the amount of fear experienced by the patient.

A common alternative theory for the effectiveness of systematic desensitization is extinction, which is a foundational principle in exposure therapy. The intended objective of exposure therapy is to generate behavior change (e.g., interacting with a feared object/situation), and to decrease, and ultimately stop, negative reactions to that feared object or situation, also known as extinction (Pavlov, 1927). When a neutral stimulus (e.g., sight of an anesthetic needle) is repeatedly paired with an unconditioned stimulus (e.g., pain from the needle prick), it will cause an unconditioned response (e.g., increased arousal; McNeil \& Kyle, 2017). Also, the neutral stimulus will become a conditioned stimulus and produce a conditioned response (e.g., seeing an anestetic needle causes increased arousal; McNeil \& Kyle, 2017). With repeated presentations of the conditioned stimulus in the absence of the unconditioned stimulus, habituation will occur and the conditioned stimulus will not produce a conditioned response (e.g., leading to "extinction" or no longer expereincing a fear response; Herry et al., 2010). Craske et al. (2008) offers a more refined explanation for effectiveness of exposure therapy based in emotional processing theory, which incorporates the concept of habituation by Groves and Thompson (1970) and Rachman's (1980) theory of corrective learning. Through emotional processing, two conditions must be met for a decrease in fear. First, the fear-related stimulus is presented and activates the fear structure. Second, the new information presented must be incompatible with information in the fear structure (Foa \& Kozak, 1986). Based on the two purported requirements for successful behavior change, higher intensity stimuli may activate the fear structure more effectively than low intensity stimuli, which in turn presents greater opportunity for acquiring incompatible information. Of note, a low intensity stimulus may not be 
sufficiently evocative enough to invalidate previously held beliefs about a fear item/situation, which would then make the exposure not as effective.

A major goal of exposure therapy is to induce learning about the feared stimulus or situation that is incompatible with the patient's negative expectations (Craske, Treanor, Conway, Zbozinek, \& Vervliet, 2014). Inhibitory learning models suggest that the original learned information about a feared stimulus or situation is not erased from memory, but that exposure produces additional, new learning about the stimulus/situation (Craske et al., 2014). It is important for the newly learned information to be incompatible to what is expected when coming in contact with the stimulus/situation (Craske et al., 2014).

Lang (1971) proposed that a fear structure is the mental representation of a stimulus (e.g., needle), response to the stimulus (e.g., increased arousal), and related meaning (e.g., I am in a dental office and need a root canal to relieve pain). In order to produce corrective learning, the fear structure must be activated and then new, incompatible information related to the fear structure must be presented (Foa \& Kozak, 1986). In other words, the existing fear structure is challenged by developing new memories of the stimulus or situation. Exposure therapy allows for experiences of corrective learning, and can produce habituation (Craske et al., 2008). Lang's (1971) conceptualization is consistent with the most current and accepted view of mechanisms involved in exposure therapy and reason for decreased response (i.e., extinction) is through the process of habituation and inhibitory learning vis a vis conditioned fear stimuli/situations (Myers \& Davis, 2007).

Expectancy violation and increased arousal are important features in effective exposure therapy (Craske et al., 2014; Culver, Stoyanova, \& Craske, 2012). In order to develop new learning about the feared object/situation, the exposures should violate the held expectations 
(e.g., frequency or intensity) about the feared object/situation (Craske et al., 2014). In addition to expectancy violation, increased arousal during the exposure task is associated with longer lasting treatment gains (Culver et al., 2012). Evidence suggest that increased arousal may optimize learning during extinction of a fear response (Cain, Blouin, \& Barad, 2004). A posited mechanism is that increased adrenergic activity improves the consolidation of memories (Culver et al., 2012).

Arousal and expectancy violation are important mechanisms in exposure treatment, but will only lead to effective treatment and positive outcomes if the patient is willing to engage in such a treatment. Consequently, it may behoove clinicians to start with low intensity exposure at the start of treatment to generate willingness to engage in treatment, and then move to higher intensity exposure that more fully violates patient expectations and generates high arousal for greater therapeutic change. The approach of starting with low intensity and increasing the level of intensity with a hierarchy is a common method in delivering exposure. Regardless of the mechanisms involved, patient adherence and level of stimulus intensity are crucial for therapeutic gains.

\section{Pharmacological Treatments for Specific Phobia}

Medications can be an effective approach to managing anxiety, at least on a temporary and time-limited basis (Farach et al., 2012). Little evidence, however, exist for medications to be a stand-alone treatment for specific phobia; nevertheless, medication is often used as an acute treatment for phobia (Bandelow et al., 2012; Choy et al., 2007). Medications used in anxiety treatment can include benzodiazepines (i.e., increases GABA levels), selective serotonin reuptake inhibitors (i.e., increases serotonin level), and/or beta-blockers (i.e., decreases 
norepinephrine levels; Smith, Robinson, \& Segal, 2017); various forms of sedation also are utilized for phobia treatment (Choy et al., 2007).

Benzodiazepines. Wilhelm and Roth (1997) found that a benzodiazepine (i.e., alprazolam) decreased anxiety during a flight for patients with flight phobia, but a week later during another flight without the medication, the patients' anxiety (e.g., self-report and physiological reactivity) was higher than a placebo group. Furthermore, a benzodiazepine (i.e., midazolam) successfully decreased self-reported anxiety immediately before a dental surgery compared to a control group, and had the same effect as a one-session psychological treatment (e.g., relaxation; Jöhren, Jackowski, Gängler, Sartory, \& Thom, 2000). Benzodiazepines may be used on a prn (i.e., when necessary) basis and short-term basis for certain phobias (e.g., flight or dental phobia; Bandelow et al., 2012).

Selective Serotonin Reuptake Inhibitors (SSRI). The efficacy, tolerance, and safety of utilizing SSRIs in the treatment of anxiety disorders has shown to be good, and often are considered the first-line in pharmacological treatment of fear (Bandelow et al., 2012). Several SSRIs (e.g., escitalopram, paroxetine, fluoxetine, fluvoxamine) have demonstrated effectiveness in treating a range of specific phobias (e.g., storms, flying, enclosed spaces, heights, dental, animals; Alamy, Wei Zhang, Varia, Davidson, \& Connor, 2008; Balon, 1999; Benjamin, BenZion, Karbofsky, \& Dannon, 2000). Despite that SSRIs appear to effectively treat phobia disorder, a meta-analysis by Roest et al. (2015) suggested that the effectiveness may be overestimated.

Beta-blockers. Another pharmacological approach is the use of beta-blockers, which target the physical symptoms often associated with acute anxiety (e.g., shaking hands, sweating, and increased heart rate) and are prescribed "off-label" (i.e., without FDA approval; Dooley, 
2015). Yaghoobi, Mahmoodiyeh, Khezri, Hashemian, and Fard (2015) found the beta-blocker propranolol effectively decreased self-reported anxiety prior to a medical surgery. Propranolol also has been extensively assessed in treating performance anxiety, and has been shown to be effective (e.g., "stage fright;” Dooley, 2015). Furthermore, Liu, Milgrom, and Fiset (1991) found that a beta-blocker (i.e., oxprenolol) resulted in lower self-reported anxiety during a needle injection in a sample of patients with high physiological arousal during a dental visit, and less pain experienced during the dental visit compared to a control group.

Sedatives. Lastly, general anesthesia and nitrous oxide have also been assessed in patients with dental phobia as a way to complete dental care-related visits (Choy et al., 2007). Specifically, Berggren and Linde (1984), comparing general anesthesia and behavioral therapy, found that in a sample of people who experienced high levels of dental anxiety and avoidance, general anesthesia was effective in completing two tooth restoration visits and lowering selfreported anxiety. Completion of the dental treatment and likelihood to attend future dental visits, however, was better for the behavioral therapy group (i.e., $92 \%$ completion rate and $78 \%$ return rate) than the anesthesia group (i.e., $69 \%$ completion rate and $53 \%$ return rate; Berggren $\&$ Linde, 1984). Willumsen, Vassend, and Hoffart (2001) found that nitrous oxide was as beneficial in lowering dental anxiety as a standard 10-week cognitive/behavioral or cognitive therapy treatment. Overall, the evidence suggests that medications have the potential to effectively decrease anxiety experienced in the moment. Armfield and Heaton (2013) posit that individuals with high levels of anxiety and acute treatment needs may benefit from the use of sedatives as a form of treatment. However, general anesthesia should be a last resort option for highly anxious individuals because it only targets the need for dental treatment rather than the anxiety associated with oral healthcare (Armfield \& Heaton, 2013). 


\section{Patient Adherence for Specific Phobia Treatments}

Regardless of the form of treatment, effectiveness of virtually all treatments are based on patient adherence, which is defined as the ability to comply with the treatment as a whole, including taking medications as prescribed, showing up for and actively participating in treatment sessions, and doing agreed-upon homework outside of sessions. The available evidence shows that treatment adherence is variable, and for some individuals, may be poor (Taylor, Abramowitz, \& McKay, 2012). Wheaton et al. (2016) found that for a sample of patients with obsessive-compulsive disorder (OCD), homework-based exposure tasks were not conducted by the patients approximately $25 \%$ time, which impacted overall treatment. Furthermore, Simpson et al. (2011) found that adherence to between-session exposure treatment (i.e., daily exposure tasks that increase in intensity day-to-day) for OCD significantly predicted decreased symptomology at the end of treatment. In particular, patients with high adherence rates early in treatment (i.e., lower intensity stimuli) resulted in greater therapeutic gains than those with high levels of adherence later in treatment (i.e., higher intensity stimuli; Simpson et al., 2011). Furthermore, patients' with high adherence to between-session "homework" activities (e.g., exposure), when receiving CBT for anxiety disorders, reported decreased anxiety compared to those with low adherence rates (Glenn et al., 2013).

The most significant issue in regard to treatment is patients who drop out prematurely, or never truly get involved from the beginning, because of negative perceptions or reactions about the treatment (Taylor et al., 2012). For example, some patients may have thoughts that certain treatments are too intense (e.g., flooding), that the treatment may not benefit them, or that they may wish to not use medications. A common problem in CBT is high dropout rates, which have been shown to range from $9-21 \%$ for generalized anxiety treatment and as high as $45 \%$ for dental 
phobia treatment (Choy et al., 2007; Taylor et al., 2012). Some possible reasons for dropout rates associated with CBT are low motivation for change, patient preference for a different treatment than what is offered, and/or patient perception that the treatment is not credible (Taylor et al., 2012). It is important to examine ways to increase adherence with exposure treatment because it is considered the leading treatment for specific phobia (Wolitzky-Taylor et al., 2008). A possible factor impacting treatment adherence and decreased dropout is patient preference regarding specific aspects of treatment (e.g., stimulus intensity for exposure). Swift, Callahan, and Vollmer (2011) found that clients receiving their preferred treatment were approximately $50 \%$ less likely to drop out of treatment. It is important, therefore, to assess patient preferences for treatment with the goal to improve overall adherence rates.

\section{Patient Preferences for Type of Treatment}

It has been shown that treatment preference is related to treatment outcomes, and patients may indicate a preference for type of treatment, which may impact overall outcomes (Swift \& Callahan, 2009; Swift et al., 2011). Patient preferences for treatment may lead therapists in deciding the actual components used in treatment (e.g., with or without exposure). Kazantzis, Ford, Paganini, Dattilio, and Farchione (2017) found that when a patient states a reluctance to receive exposure treatment, a clinician is less likely to include exposure as part of treatment (e.g., CBT without exposure). A meta-analysis by Adamson et al. (2008) found that when patients' preference for musculoskeletal pain treatment matches the intervention received, outcomes are improved. McPherson, Britton, and Wennberg (1997) stated that patient preference and treatment effect are intertwined, but often not examined in randomized control trials. Treatment preference is based on knowledge or assumed knowledge on the part of the patient, and how the clinician describes/presents the treatment. Patients may use a myriad of sources to acquire information 
about treatments, including the internet, which may be accurate or inaccurate depending on the source of information. Ipser, Dewing, and Stein (2007) state that the quality of information on anxiety treatment found on the internet, including specific phobia, was moderate to poor, and the users may be presented with misinformation on how to treat anxiety disorders. Furthermore, general knowledge about exposure among lay people may be misguided, such that they may view exposure therapy as unhelpful, unacceptable, and unethical to use for treatment of anxiety disorders (Richard \& Gloster, 2007).

Medication versus psychotherapeutic treatment. Preference for pharmacological over psychological treatment may differ across disorders, but overwhelmingly for anxiety disorders, the preferred treatment among patients is psychotherapy (Deacon \& Abramowitz, 2005; McHugh \& Whitton, 2013). A meta-analysis indicated that $75 \%$ of patients with anxiety disorders prefer psychological treatments over pharmacological ones (McHugh \& Whitton, 2013). In a study examining treatment preference for older adults diagnosed with an anxiety disorder, $76 \%$ reported a preference for psychological treatment over a pharmacological approach (i.e., 13\%) or a combined approach (i.e., 11\%; Mohlman, 2012). It has been shown that pharmacological treatment and CBT are equally rated by patients diagnosed with an anxiety disorder as "favorable," but CBT is rated as more acceptable and effective than pharmacological treatment (Deacon \& Abramowitz, 2005). Of 103 outpatients diagnosed with an anxiety disorder, there were $74.3 \%$ who reported CBT as a first-choice treatment, compared to $25.7 \%$ indicating a firstchoice preference for medications (Deacon \& Abramowitz, 2005). Additionally, 13\% of the patients indicated a preference to not use medications for anxiety treatment, while $100 \%$ of the patients were favorable about CBT as a treatment method, likely including some who would prefer its use in conjunction with medications (Deacon \& Abramowitz, 2005). Wheaton, 
Carpenter, Kalanthroff, Foa, and Simpson (2016), however, found that 32\% of OCD patients indicated a preference for medication (e.g., risperidone) over exposure treatment. Furthermore, Jöhren et al. (2000) found that some participants were unwilling to receive psychotherapy and requested pharmacological treatment with dental phobia; however, the authors did not specify the percentage of the sample unwilling to receive psychotherapy. Finally, a meta-analysis on preference for treatment of posttraumatic stress disorder (PTSD) demonstrated a strong preference for exposure therapy as opposed to a pharmacological approach.

The differences in percentages of patients preferring a certain treatment over another indicate that therapy should be individually tailored to increase adherence and utilization rates. Treatment should depend, in part, on the preference of the patient. Some patients, for example, may indicate a preference for not receiving medications and vice versa. If the treatment prescribed is different than requested, treatment adherence may be low.

CBT versus other psychotherapeutic treatments. Literature examining patient preferences for various forms of psychological treatment (e.g., psychodynamic versus CBT) is sparse. Bragesjö, Clinton, and Sandell (2004), however, found that the general public rates CBT as more credible, helpful, and preferred compared to psychodynamic psychotherapy. Similarly, Frövenholt, Bragesjö, Clinton, and Sandell (2007) found that the general public rated an overwhelming preference for CBT over psychodynamic or cognitive therapy; however, patient samples were more likely to prefer psychodynamic and cognitive therapy over CBT (Frövenholt et al., 2007). In a study examining treatment preference for older adults diagnosed with anxiety problems, 29\% reported a preference for CBT, which was greater than supportive therapy (i.e., 27\%), psychodynamic therapy (i.e., 7\%), and acceptance-based therapy (i.e., 4\%; Mohlman, 2012). Furthermore, Johansson, Nyblom, Carlbring, Cuijpers, and Andersson (2013) found that 
when given a choice between internet-based psychodynamic psychotherapy (IPDT) and internetbased CBT (ICBT) for treatment of major depressive disorder, patients were two times as likely to choose the ICBT over the IPDT.

\section{Increasing Willingness to Engage in Exposure Treatment}

Given that CBT, which includes exposure therapy, is the gold standard and preferred by some patients and particularly those with an anxiety disorder, it is important to examine ways to improve willingness to engage in the treatment. Treatment preferences have been seen to impact overall engagement and utilization of treatment, and it is important to examine preferences regarding factors that are exposure treatment-specific. For example, level of stimuli intensity is particularly important in exposure therapy, as higher intensity stimuli typically are associated with the ultimate goal of exposure treatment. If the intensity of a stimulus is too great, however, then adherence might be low. On the other hand, if the intensity of the stimulus is too weak, then little to no therapeutic change may occur. Systematic desensitization paved the way for the development and fine tuning of exposure therapy. Wolpe (1958) made the assumption that patients should experience little to no anxiety during the process of exposure to allow counterconditioning to occur. Current understandings of exposure therapy do not support that theory, but Wolpe may have uncovered something important in how exposure should be presented to patients (e.g., starting with low intensity) to increase treatment adherence. For example, a recent study found good adherence rates (i.e., watching an exposure video more than one time a day on average) of participants with high levels of dental care-related fear in a twoweek exposure treatment, which could be attributed to the low intensity of the videos watched (Arias \& McNeil, 2019). Moreover, individuals appear to prefer a CBT- and/or exposure-based treatment for PTSD, but rate exposure-based treatments as highly uncomfortable (Tarrier, 
Liversidge, \& Gregg, 2006). Thus, easing into exposure stimuli (i.e., low intensity first) may decrease thoughts about experiencing discomfort within treatment.

It has been shown that utilizing a "random" approach to presentation of graded exposure stimuli (e.g., varying levels of difficulty) is as effective in treating phobia with exposure in comparison to proceeding sequentially from the lowest to the highest (Lang \& Craske, 2000;

Rowe \& Craske, 1998). Masters et al. (1987) suggest that stimuli presentation should start at the lowest and gradually increase for highest levels of patient adherence, but going in a descending order or only completing the highest three exposure steps also demonstrates effective fear reduction. However, experiencing the higher levels of stimuli intensity, particularly early in treatment, may lead to increased patient dropout because of the greater distress (Masters et al., 1987). Thus, it may not be necessary in terms of efficacy to present the exposure stimuli in ascending order, but that approach may be crucial for some patients to stay in treatment. For example, if the patient prefers to limit the distress and anxiety experienced, then using a low intensity stimulus to begin with may improve treatment adherence and decrease dropout. Although many studies have assessed patient preference and beliefs about exposure therapy compared to medication or other psychotherapy treatments (Jaeger, Echiverri, Zoellner, Post, \& Feeny, 2009), few studies have directly assessed patient preference for various formats (e.g., low intensity versus high intensity content) of delivering exposure therapy. Thus, it is important to assess patient preferences for stimulus intensity and presentational approach in order to increase overall treatment adherence.

\section{Statement of the Problem}

A common issue in the delivery of psychotherapy is adherence at levels that inhibit therapeutic gains, especially when exposure therapy is the proposed treatment (Simpson et al., 
2011; Taylor et al., 2012; Wheaton et al., 2016). Nevertheless, previous research has demonstrated that exposure therapy can effectively be used to treat phobias and other anxiety disorders (Hellström \& Öst, 1995; Michelson, Mavissakalian, Marchione, Dancu, \& Greenwald, 1986; Schneider, Mataix-Cols, Marks, \& Bachofen, 2005). There are various options for treatment of specific phobia (e.g., exposure, medications, supportive therapy, muscle relaxation), and each of these may be affected by the patient's decision to not pursue treatment and to continue avoidance. Patients may be hesitant to receive exposure treatment because the goal is to challenge fears by coming in contact with the feared stimulus/situation. These avoidant behaviors with many specific phobias are possible because of their circumscribed effects on quality of life. Little is known about preferences for treatment among individuals in the general population who have specific phobia. The intensity of the presented exposure stimuli is one factor that may influence adherence to treatment. It is important to assess how to balance factors that might increase patient adherence (e.g., using low intensity stimuli) versus features that may make a treatment effective (e.g., using high intensity stimuli) in order to evoke therapeutic change. Low-intensity stimuli might increase patient buy-in and also lead to increased adherence when a part of an escalating hierarchy of exposure stimuli. Patient preference for treatment of phobia, thus, is an important factor to consider when developing and utilizing evidenced-based treatments. Generally, it is important to assess patients' willingness to engage in exposure treatment.

\section{Hypotheses}

\section{Research Question 1: Preference for Treatment}

What percent of the sample from the general population in the USA who report high levels of dental fear/anxiety prefer which types of specific phobia treatments? 
Hypothesis 1. A majority of participants will report higher levels of preference for systematic desensitization over exposure, flooding, arousal control alone, medications, or combinations of these various methods.

\section{Research Question 2: Preference for Stimuli Order}

What percent of the sample from the general population in the USA who report high levels of dental fear/anxiety prefer a certain order of stimulus intensity presentation for exposure therapy?

Hypothesis 2. A majority of participants will prefer a gradual accelerating approach (low to high intensity) relative to a high-intensity exposure, low-intensity exposure, gradual decelerating approach (high to low intensity), or a random approach.

\section{Research Question 3: Perceived Effectiveness and Willingness to Engage in Treatment}

How do participants who report high levels of dental fear/anxiety rate the effectiveness of exposure therapy and their willingness to engage in exposure differ for low and a high intensity stimuli presentation?

Hypothesis 3a. A majority of participants will choose to view low intensity anxietyrelated video stimuli rather than high intensity anxiety-related video stimuli, as a measure of behavioral preference for low intensity exposure-related material.

Hypothesis 3b. A majority of participants will rate the high intensity exposure as more effective in treating their phobia than the low intensity exposure.

Hypothesis 3c. A majority of participants will report greater willingness to engage in the low intensity exposure compared to the high intensity exposure.

\section{Method}

\section{Participants}


Power was determined by the planned analysis of hypothesis 1 , utilizing a repeated measure Analysis of Variance (ANOVA) with one group rating preference on four different treatment options. According to a power analysis program, G*Power 3 (Faul, Erdfelder, Lang, \& Buchner, 2007), to achieve a power of $\varphi=.95$ at a small effect size of .10 with four within measurements, a sample size of 216 was suggested. In order to allow for incomplete responses, dropout, and excluding participants based on the exclusion criteria, a total of 1,065 participants were screened in order to recruit 300 participants.

Data from participants were collected via “Amazon Mechanical Turk (M-Turk),” which is a web-based tool used for data collection across the world (www.mturk.com). M-Turk workers are compensated for completing "Human Intelligence Tasks" (e.g., completing the proposed study). MTurk is regarded as an inexpensive and effective method of obtaining data from diverse samples, which include greater diversity than college student participant pools (Buhrmester, Kwang, \& Gosling, 2011). Behavioral and psychological research often utilizes MTurk as a means to collect data, and MTurk-based participants have been shown to have comparable responses to participants who are part of in-person experiments (Casler, Bickel, \& Hackett, 2013; Crano, Brewer, \& Lac, 2014; Mason \& Suri, 2012).

Inclusion for participation included self-reported fluency in the English language, being 18 years of age or older, indicating residency in the USA, reporting significant dental carerelated fear/anxiety (e.g., 4+ out of 5 on a single item dental fear question), and completing the screening phase of the study. Exclusion criteria were self-report of current treatment for phobia or self-report of taking anti-anxiety medications, and if participants had identical ip addresses (i.e., three or more times - see validity check section below for more information). Participants were compensated after completing each phase of the study. 
This study adhered to the guidelines presented by the American Psychological Association for treatment of human research participants. In order to participate, subjects agreed to an informed consent form that was approved by the West Virginia University Institutional Review Board, protocol \#1801957814.

\section{Video Stimuli}

In a prior study on treatment of high dental care-related fear and anxiety, as well as phobia (McNeil, 2019), 10 publicly-available video clips were identified from YouTube ${ }^{\mathrm{TM}}$. They were selected on the basis of being sequential, from low intensity (e.g., entering a dental office) to high intensity (e.g., highly magnified tooth crown preparation and placement). Subjective Units of Distress Scale (SUDS; Wolpe, 1973) ratings (i.e., 0-100) were obtained from 29 patients who participated in systematic desensitization treatment using an Ipad to deliver the stimuli in a dental operatory. From these 10 videos, two were selected (i.e., video 1 and video 5). Refer to Appendix A for content of the 10 videos. The videos were selected based on similar length (i.e., 120 seconds) and self-reported ratings of anxiety experienced when viewing the videos.

In the prior study (McNeil, 2019), participants were allowed to watch each of the 10 videos up to three times and provided SUDS ratings (i.e., highest anxiety experienced during the video) after watching the video. Mean SUDS ratings across each of the video trials were calculated to represent anxiety experienced during the 10 videos. Refer to Table 1 for mean anxiety ratings for the 10 videos. Based on the ratings, video 1 (i.e., low intensity) and video 5 (i.e., high intensity) were selected. A paired samples $t$-test demonstrated that the high intensity video $(M=71.1, S D=19.7)$ was rated as significantly higher than the low intensity video $(M=$ $43.3, S D=22.1)$ in terms of self-reported anxiety, $t(28)=7.86, p<.001$. 
There were 30 -second trailers created from the two videos and shown to the participants as an example for the different video intensities (e.g., low and high). The low intensity exposure video depicted a patient walking into a dental clinic (i.e., video 1 in Appendix A), having a short conversation with the dental hygienist, and receiving an examination and prophylaxis by a dental hygienist. The high intensity exposure video included a patient lying supine in a dental chair receiving injections (i.e., video 5 in Appendix A).

\section{Descriptions of Treatment Options}

Definitions from the APA Dictionary of Psychology (American Psychological Association, 2015) were identified and the different treatment descriptions were presented to participants who rated preference, expected efficacy, and willingness to engage in the treatment. Refer to Appendix A.

\section{Self-Report Measures}

Demographic and general dental information questionnaire. The questionnaire consists of 24-items asking about the participants' age, sex, race/ethnicity, and general dental information, as well as content related to a larger study. Refer to Appendix C for specific demographic questions.

Dental Fear Survey (DFS; Kleinknecht, Klepac, \& Alexander, 1973). The DFS has 20 self-report items rated on a 5-point Likert-type scale and has a total score ranging from 20 to 100, with higher scores being indicative of increased anxiety and fear related to dental care (Kleinknecht et al., 1973). Refer to Appendix D. The measure assesses responses (i.e., physiological and behavioral) to specific dental situation and circumstances and reflects general dental care-related anxiety/fear. The DFS consists of three subscales: Dental avoidance and anxiety, Fear of dental stimuli/procedures, and Arousal associated with dental treatment. The 
DFS also has a single omnibus item, which was used in the screening phase as a qualification to participate in the study (i.e., score of $4+$ out of 5). The single item has demonstrated high correlation with the DFS total score (McGlynn, McNeil, Gallagher, \& Vrana, 1987). The DFS has low demand on the participant (e.g., time and cognitive requirements), and is widely used in behavioral dentistry research. The DFS has demonstrated good reliability (test-retest $r=.88$ ) and validity ( $\alpha$ 's $\geq$.75; Heaton, Carlson, Smith, Baer, \& De Leeuw, 2007; McGlynn et al., 1987).

Preference, treatment effectiveness, and willingness to engage in treatment. In order to assess preference for types of treatments (i.e., exposure, relaxation, systematic desensitization, and flooding), a single-item question was used rated on a 5-point Likert-type scale, which is based on typical approach used for studies included in a meta-analysis examining treatment preferences (Lindhiem, Bennett, Trentacosta, \& McLear, 2014). Refer to Appendix E. Also in order to assess preference for types of treatments, participants were asked to rank order treatments from most preferred (i.e., 1) to least preferred (i.e., 6), which included common approaches for managing phobia (i.e., pharmacological, relaxation, nitrous oxide, systematic desensitization, exposure, and flooding). Refer to Appendix F.

In order to assess preference for exposure stimuli presentation, participants rated preference for low intensity stimuli and high intensity stimuli with a single-item question rated on a 5-point Likert-type scale. Refer to Appendix E. Also, participants were asked to rank order preference for how stimuli should be presented sequentially to treat their dental fear. Refer to Appendix G. Similarly in regard to the low intensity and high intensity exposure stimuli, treatment effectiveness and willingness to engage in treatment were assessed in the same manner as the first preference question (i.e., 5-point scale). Refer to Appendices H and I. 
Validity checks. In order to ensure accurate responding in the study and that participants watched the exposure video(s), participants answered five validity checks throughout their participation in the study (i.e., two in the screening phase and three in the preference phase). Refer to Appendix J. Participants who answered both validity check questions correctly in the screening phase were included in the screening analyses. Also, participants who answered two or more of the three validity check questions correctly in the preference phase were included in the analyses. Finally, participants with three or more identical ip addresses were dropped from the analysis to prevent the possibility of duplicate responses from one household. Two identical ip address were allowed because it was thought reasonable that two people in the same household may both be MTurk workers.

\section{Behavioral Preference Measure}

The two 30-second trailers (i.e., low intensity and high intensity exposure videos) were presented to the participants in a counterbalanced order. Then participants had the opportunity to choose to watch the low intensity video, the high intensity video, a black screen (e.g., avoidance), or the combination of the three choices a total number of three times. Behavioral preference for treatment was calculated by number of times each of the options was viewed.

\section{Procedure}

\section{Screening Phase}

Participants were invited via MTurk to complete the screening phase, which consisted of the demographic questionnaire, DFS, and two validity questions, as well as two other instruments not related to the current study. If the participant reported high levels of dental carerelated fear (i.e., 4+ on the single DFS item), then they were invited to participate in the preference phase of the study. All participants were provided $25 \varnothing$ after completing the screening 
phase. Those who did not qualify for the preference phase were thanked, and those who did qualify were invited to participate in the preference phase.

\section{Preference Phase}

Participants were provided a series of treatment options with definitions (i.e., systematic desensitization, exposure, flooding, and relaxation), and then asked to rank order the types of treatments based on preference. After ranking the various types of treatments, participants viewed two 30-second trailer videos (i.e., low intensity and high intensity). Order of video intensity was randomly assigned. After viewing one of the trailers, participants rated level of preference, perceived efficacy, and their own willingness to engage in that method of exposure therapy (i.e., low intensity or high intensity). After answering the questions, participants watched the second trailer (i.e., high intensity or low intensity), and rated level of preference, perceived efficacy, and their own willingness to engage in the method. Then, participants were offered their first choice in which video to watch, the 120 -second low intensity video, the 120 -second high intensity video, or the120-second black screen video. After watching their first choice of video, participants were offered again the choice of video to watch next (i.e., 120-second low intensity video, 120-second high intensity video, or a 120 -second black screen). Finally, participants were again offered the choice of video to watch a third time. After watching the video(s) three times, participants' rank ordered their preference for the presentation of exposure stimuli. Participants were asked to answer a validity check question after watching each video. Upon completion of the preference phase, participants were awarded an additional $\$ 1.00$.

\section{Study Analyses}

The first hypothesis was assessed by utilizing a repeated measures ANOVA to examine preferences for different types of treatment for dental fear/anxiety. Furthermore, the rank order 
and percentages of the various types of treatment approaches were examined via Friedman tests, and planned post-hoc contrasts were examined with Wilcoxon signed-rank tests.

The second hypothesis was assessed by utilizing a repeated measures ANOVA to examine preferences for various methods for presenting exposure stimuli. Rank order and percentages for exposure stimuli presentation were also examined via Friedman tests, and planned post-hoc contrasts were examined with Wilcoxon signed-rank tests. Finally, a Latent Class Analysis was conducted to assess how different groups of participants emerged based on which videos were watched over the three trials.

Paired sample $t$-tests were used to assess the third hypothesis in regard to preference, perceived effectiveness, and willingness to engage in the two methods for delivering exposure therapy (i.e., low versus high intensity).

\section{Results}

A total of 900 participants were included in the analyses for the screening phase of the study, and of those participants, 235 were included in the analyses for preference phase of the study. Refer to figure 1 for a flowchart of participant inclusion/exclusion. Table 2 includes demographic characteristics and tests for possible group differences between those in the screening and those in the preference phase.

\section{Hypothesis 1}

To assess preferences for various specific phobia treatments, a repeated measure ANOVA was conducted. Results indicated a significant difference of preference rating (i.e., 0-4 scale) among the four possible treatments, $F(2.83,571.776)=54.34, p<.001$, partial eta ${ }^{2}=.212$. Relaxation $(M=2.0 S D=1.1)$ was rated as more preferred than Systematic Desensitization $(M=$ $1.8 S D=1.2)$, Exposure $(M=1.6 S D=1.2)$, and Flooding $(M=.9 S D=1.2)$. Systematic 
Desensitization and Exposure did not differ, but both were rated as more preferred than flooding. Refer to Figure 2.

Also, a Friedman test was used to examine ranked preferences (i.e., 1 most preferred to 6 least preferred) for various types of specific phobia treatment. There was a significant difference in participant preference rankings, $\chi^{2}(5)=283.06, p<0.001$. Planned post-hoc contrasts via Wilcoxon signed-rank test comparing systematic desensitization and the other options were conducted with a Bonferroni correction (i.e., $p<0.01$ ). Systematic Desensitization was ranked as less preferred than Relaxation, more preferred than Exposure or Flooding, and did not differ from Pharmacological or Nitrous Oxide. Refer to Figure 3.

A post hoc test was conducted to examine participants' top preferred treatment option (i.e., relaxation) compared to the other treatments with a Wilcoxon signed-rank test with a Bonferroni correction (i.e., $p<0.01$ ). Relaxation was ranked as more preferred than Systematic Desensitization, Exposure, and Flooding.

\section{Hypothesis 2}

A Friedman test was utilized to assess ranked preference for various exposure treatment methods. There was a significant difference in participant preference ratings for various exposure methods, $\chi^{2}(4)=239.35, p<0.001$. Planned post hoc contrasts via a Wilcoxon signed-rank test comparing a gradual accelerating approach and the other options was conducted with a Bonferroni correction (i.e., $p<0.0125$ ). The gradual accelerating approach (i.e., Low to High) was ranked as less preferred than the low-intensity approach, and ranked as more preferred than the random approach, the gradual decelerating approach (i.e., high to low intensity), and the high-intensity approach. Refer to Figure 4. 
A post hoc test was conducted to examine participants top preferred exposure method (i.e., Low intensity) compared to the other methods with a Wilcoxon signed-rank test with a Bonferroni correction (i.e., $p<0.0125$ ). The low-intensity approached was ranked as more preferred than the gradual accelerating approach, random approach, gradual decelerating approach (i.e., high to low intensity), and high-intensity approach.

\section{Hypothesis 3a}

A paired samples $t$-test was conducted to examine participant ratings of perceived preference for the low intensity versus the high intensity video content. Participants self-reported higher preference for the low intensity video content $(M=2.5, S D=1.2)$ compared to the high intensity content video $(M=1.1, S D=1.3), t(234)=12.98, p<.001, d=1.12$.

In order to examine level of willingness to engage in various exposure treatments (e.g., low intensity versus high intensity), a repeated measures ANOVA was conducted based on total number of times the different video contents were watched (i.e., 0-3 times). Analysis indicated a significant main effect for total videos watched, $F(1.873,438.392)=20.34, p<.001$, partial eta ${ }^{2}$ $=.079$, such that low intensity $(M=1.3, S D=1.0)$ and the black screen $(M=1.1, S D=1.1)$ were watched more than the high intensity $(M=.6, S D=.9)$. Viewing of the black screen and low intensity videos did not differ.

Total number of times each video type was watched (i.e., 0-3) was used to examine participant preference for each video type (i.e., low intensity preference, high intensity preference, avoidance preference, and no preference). A low intensity preference would correspond to participants who watched the low intensity video two or more times, a high intensity preferences are those who watched the high intensity video two or more times, an avoidance preference are individuals who watched the black screen video two or more times, and 
no preference includes participants who watched each video type only once. A total of 93 (39.6\%) participants demonstrated a low intensity preference, 35 (14.9\%) showed a high intensity preference, 77 (32.8\%) demonstrated an avoidance preference, and $30(12.8 \%)$ exhibited no video preference.

A Latent Class Analysis was utilized to assess for differential patterns of watching the exposure videos. The number of classes extracted were based on various fit indices across various models with an iterative process (e.g., akaike information criterion, bayesian information criterion, entropy, and bootstrapped likelihood ratio test; Jung \& Wickrama, 2008; Wang \& Wang, 2012). Results suggest a two-class solution with a "Prefer Low Activation" group (69.5\%) and an "Avoidant" group (30.5\%). Refer to Table 3 for fit indices and to Figure 5 for class probabilities with each video choice across the three trials (e.g., the likelihood that a participant in one of the determined groups would select the low intensity, high intensity, or black screen at each trial). Thus, class probability ranges from $0 \%$ (i.e., no chance of selecting the video type) to $100 \%$ (i.e., participant will definitely choose the video type). The Prefer Low Activation group had a probability of $60 \%$ for choosing the low intensity video for the first trial, a $57 \%$ for the second trial, and $47 \%$ chance of choosing it for the third trial. For this group, participants' probability of avoiding (i.e., choosing the black screen) increased with each trial, $7 \%, 15 \%$, and $29 \%$, respectively. Thus, participants in this group were more likely at each subsequent trial to avoid rather than watch on of the exposure videos. Finally, the Avoidant group consistently had a greater probability of avoiding the videos over the three trials with $74 \%$ in trial $1,88 \%$ in trial 2 , and $86 \%$ in trial 3 . Furthermore, the probability of selecting the high intensity video was the least likely in this group.

\section{Hypothesis $3 b$}


To assess participant ratings of perceived effectiveness for the low intensity versus the high intensity exposure treatment approach, a paired samples $t$-test was utilized. Analysis indicated that participants rated the low intensity exposure $(M=1.8, S D=1.4)$ as likely to be more effective than the high intensity exposure $(M=1.2, S D=1.3), t(234)=6.27, p<.001, d=$ 0.44 .

\section{Hypothesis 3c}

To assess participant willingness to engage in low intensity treatment versus high intensity treatment, a paired samples $t$-test was utilized. Analysis indicated that participants rated more willingness to engage in the low intensity exposure $(M=2.5, S D=1.2)$ than the high intensity exposure $(M=1.3, S D=1.4), t(234)=11.44, p<.001, d=0.92$.

\section{Discussion}

A goal of this study was to examine patient preferences for available treatments for specific phobia, with dental care-related fear, anxiety, and phobia, as an exemplar. Previous studies have compared patient preferences for pharmacological versus psychological treatment (McHugh \& Whitton, 2013) or CBT versus other psychotherapeutic treatments (Frövenholt et al., 2007). To date, however, no one has assessed patient treatment preference with an extensive list of treatments (e.g., medications, exposure, relaxation, nitrous oxide, flooding). Overall, participants appear to prefer the least intensive approach (e.g., relaxation or a low intensity exposure). The most illuminating results of the current study may be that participants rated relaxation as a more preferred treatment than other options, including medications and nitrous oxide. Although participants rating relaxation as the most preferred option for their dental fear/anxiety was surprising, evidence supports the approach specifically with dental phobia (Armfield \& Heaton, 2013). Relaxation can help with more than the fear and anxiety experienced 
and may decrease overall pain experienced during a dental visit (Armfield \& Heaton, 2013).

Furthermore, the results are consistent with patient preference for CBT treatments compared to pharmacological treatment for other specific phobias and anxiety disorders more generally (McHugh \& Whitton, 2013). The findings suggest that participants may want help reducing stress experienced at a dental visit via behavioral training rather than using medications/sedatives or other psychological approaches (e.g., exposure).

Another goal of the current study was to examine patient preference for specific components involved in exposure therapy (e.g., order of stimuli presentation). Some key factors that impact exposure effectiveness are learning new information that violates a previously held fear-structure and increased arousal during the exposure (Craske et al., 2014; Culver et al., 2012; Foa \& Kozak, 1986). Therefore, it was hypothesized that participants would rate a gradual accelerating intensity as most preferred; however, participants consistently demonstrated a preference for the low intensity stimuli, which in retrospect may not be surprising given the nature of exposure therapy (e.g., confronting a fear) and related high levels of dropout and low levels of adherence (Choy et al., 2007; Taylor et al., 2012). The self-reported preference for low intensity versus high intensity exposure stimuli was further supported by actual behaviors. Participants were more likely to watch the low intensity video or avoid the videos completely than watch the high intensity video across the three trials. The findings suggest when presented the opportunity to choose between low intensity, high intensity, or avoid altogether, participants were more likely to choose the low intensity stimuli or avoid the stimuli.

The Latent Class Analysis supports these findings as well and suggests that there were two distinct groups. Given the previous results of a preference for low intensity or avoidance, it is not surprising that the most consistent group (e.g., watched the same exposure stimuli intensity 
over the three trials) was those who avoided the videos completely (i.e., Avoidant group). The second group (i.e., a Low to Avoidant group) again demonstrates a preference for low intensity stimuli or avoidance, and these individuals appear to be willing to engage in this type of treatment, at least at low levels. It has been shown that a low intensity exposure for dental fear, anxiety, and phobia over a two-week period was effective in decreasing self-reported anxiety during a behavioral avoidance task (Arias \& McNeil, 2019). Results suggest that with each trial, however, the probability of participants avoiding the videos increased, which is inconsistent with Simpson et al. (2011). The difference could be due to the participants in the present study watched the same low intensity content rather than systematically increasing stimuli intensity as in Simpson et al.'s (2011) study. The variety of low intensity stimuli, therefore, may have improved treatment adherence rates more than just the low intensity stimuli. Based on Arias and McNeil (2019), however, watching a low intensity exposure may need to persist across several weeks rather than one session. Furthermore, participants on average were only watching the low intensity exposure once per day (Arias \& McNeil, 2019), which is consistent with the behavioral pattern of the present participants (i.e., increasing likelihood of choosing the avoid option as the participants progressed through the three trials).

Finally, the current study assessed patient perceptions about exposure therapy and the various methods to present stimuli. Similar to the previous findings, participants self-reported the low intensity exposure as more preferred than the high intensity exposure. Inconsistent with the proposed hypothesis, however, participants rated the low intensity exposure as likely to be more effective than the high intensity exposure. The differences, however, may not be clinically significant, based on the small effect sizes. Nonetheless, participants' perception for effectiveness of the two treatment approaches were rated as moderate, which is consistent with 
previous findings (Becker, Darius, \& Schaumberg, 2007). Lastly, participants reported a greater willingness to watch the low intensity exposure videos as compared to watching the high intensity videos as a method of exposure treatment. Previous research suggests that patients with high levels of dental care-related fear/anxiety are quite adherent when the stimuli presented was considered by the patients as low intensity (Arias \& McNeil, 2019). The self-reported willingness to engage in low intensity exposure was further supported by the results of the Latent Class Analysis; where, most participants (regardless of class) avoided watching the high intensity videos.

The results of this study highlight important factors that can be considered to improve efficacy of specific phobia treatment. In particular, clinicians should consider patient preferences for treatment because they are inherently tied to therapeutic outcomes and patient adherence. A significant finding was participant preferences for relaxation as a treatment option, which could easily be integrated into dental practices. Dental care providers can equip and train their patients to utilize relaxation approaches within the office, which can decrease patient and provider burden. Furthermore, dental care providers can offer relaxation as a treatment for those with high levels of dental fear/anxiety with other commonly provided options (e.g., sedation) and allow the patient to choose based on their preference. Another important finding of this study is that it may behoove clinicians to consider patient preference when delivering exposure therapy, such as offering a low intensity approach rather than the typical gradual accelerating approach. Also, based on previous findings (i.e., Arias \& McNeil, 2019) and the results of this study, it may add to the theoretical approach of exposure therapy, such that a low intensity approach may be effective and accepted by individuals with dental phobia. Moreover, this study highlights on perhaps adopting a low intensity approach at first to increase buy-in and adherence before 
moving to higher intensity exposure. Overall, it is important to consider patient preferences in all areas of treatment, which can improve treatment outcomes and adherence rates.

This study is not without limitations. Despite the positive aspects of MTurk as a source to collect participant responses, MTurk samples, compared to national samples, may be less representative of USA demographics (Berinsky, Huber, \& Lenz, 2012). Overall, MTurk samples appear to have higher educated participants (e.g., college degree), more likely to identify as female, and are more likely to report living in urban areas when compared to national norms (Huff \& Tingley, 2015). A potential problem with MTurk samples is a higher social desirability bias effect and possible lower engagement compared to research conducted in-person (Peer, Vosgerau, \& Acquisti, 2014). Despite the potential limitations of MTurk, it was chosen to recruit participants because of the need for a large, generalizable population.

The preference phase of the study had more women enrolled than men, which is a limitation. However, the rates of men enrolled in the screening phase was approximately even with women. The difference in men who qualified for the preference phase may not be all that surprising. It has been shown that men often report lower anxiety levels, whereas women report higher ones (Craske, 2003). Due to this fact, it may have been better to lower the inclusion criteria of reporting a $4+$ on the DFS item 20 for men to $3+$ to have a similar distribution in the preference phase. Future studies can examine how men who rate a 3 on the DFS item 20 differ from those who rate a 4 on the item.

Another potential limitation of this study is that there is no way of knowing if the participants watched the videos attentively, or at all. Steps were taken, however, to ensure the participants watched the videos in their entirety and the study's design even provided an option to avoid (e.g., black screen). Future research can examine if videos watched in a clinic setting 
versus online make a difference in self-reported preference for exposure methods. Also, participant ratings of perceived efficacy for the exposure methods (i.e., low intensity and high intensity) may have been confounded by their self-reported preference, which may explain why participants rated the low intensity approach has more effective than the high intensity approach. Thus, future studies can examine in greater detail why individuals prefer one method over the other. Lastly, the study did not provide exposure treatment to the participants, and so the relation of preferences to efficacy is unknown. Future research should investigate whether educating patients about the efficacy and speed of impact affects treatment preferences.

Taking into consideration patient preferences for treatment options and methods provides a host of advantages. Ultimately, the goal for treatments is to be effective, but it is critical that they be accepted and utilized by patients (McNeil, 2011). A gold standard treatment is useless if patients are not willing to utilize it. Furthermore, patient preference for various treatments and perceived effectiveness of the treatments can impact the level of commitment to the regimen, which can impact treatment outcomes. This study directly assessed preferences for treatment of specific phobia, and various delivery methods. Results demonstrated that low intensity exposure was preferred by those with high levels of dental care-related fear and anxiety, was seen as effective, and was associated with a willingness to engage in the treatment. Furthermore, participants rated relaxation as the most preferred type of treatment, which could have a direct impact on dental care-related services and should influence the current state of oral healthcare. 


\section{References}

Adamson, S. J., Bland, J. M., Hay, E. M., Johnson, R. E., Jones, G. T., Kitchener, H., ... Torgerson, D. J. (2008). Patients' preferences within randomised trials: Systematic review and patient level meta-analysis. British Medical Journal, 337, 1-8. https://doi.org/10.1136/bmj.a1864

Alamy, S., Wei Zhang, Varia, I., Davidson, J. R., \& Connor, K. M. (2008). Escitalopram in specific phobia: Results of a placebo-controlled pilot trial. Journal of Psychopharmacology, 22(2), 157-161. https://doi.org/10.1177/0269881107080796

American Psychiatric Association. (2013). Diagnostic and statistical manual of mental disorders (5th ed.). Washington DC: American Psychiatric Publishing.

American Psychological Association. (2015). APA dictionary of psychology (2nd ed.; G. R. VandenBos, ed.). Washington, DC: American Psychological Association.

Anestis, M. D., Selby, E. A., Fink, E. L., \& Joiner, T. E. (2007). The multifaceted role of distress tolerance in dysregulated eating behaviors. International Journal of Eating Disorders, 40(8), 718-726. https://doi.org/10.1002/eat.20471

Arias, M. C., \& McNeil, D. W. (2019). Smartphone-based exposure treatment for dental phobia: A pilot randomized control trial. Journal of Public Health Dentistry, 1-8. https://doi.org/https://doi.org/10.1111/jphd.12340

Armfield, J., \& Heaton, L. (2013). Management of fear and anxiety in the dental clinic: A review. Australian Dental Journal, 58(4), 390-407. https://doi.org/10.1111/adj.12118

Balon, R. (1999). Fluvoxamine for phobia of storms. Acta Psychiatrica Scandinavica, 100(3), 244-245. Retrieved from http://www.embase.com/search/results?subaction=viewrecord\&from=export\&id=L2940909 
Bandelow, B., Sher, L., Bunevicius, R., Hollander, E., Kasper, S., Zohar, J., \& Möller, H.-J. (2012). Guidelines for the pharmacological treatment of anxiety disorders, obsessivecompulsive disorder and posttraumatic stress disorder in primary care. International Journal of Psychiatry in Clinical Practice, 16(2), 77-84.

https://doi.org/10.3109/13651501.2012.667114

Becker, C. B., Darius, E., \& Schaumberg, K. (2007). An analog study of patient preferences for exposure versus alternative treatments for posttraumatic stress disorder. Behaviour Research and Therapy, 45(12), 2861-2873. https://doi.org/10.1016/j.brat.2007.05.006

Benjamin, J., Ben-Zion, I. Z., Karbofsky, E., \& Dannon, P. (2000). Double-blind placebocontrolled pilot study of paroxetine for specific phobia. Psychopharmacology, 149(2), 194196. Retrieved from http://www.ncbi.nlm.nih.gov/pubmed/10805616

Berggren, U., \& Linde, A. (1984). Dental fear and avoidance: A comparison of two modes of treatment. Journal of Dental Research, 63(10), 1223-1227. https://doi.org/10.1177/00220345840630101201

Berinsky, A. J., Huber, G. A., \& Lenz, G. S. (2012). Evaluating online labor markets for experimental research: Amazon.com's Mechanical Turk. Political Analysis, 20(3), 351368. https://doi.org/10.1093/pan/mpr057

Bragesjö, M., Clinton, D., \& Sandell, R. (2004). The credibility of psychodynamic, cognitive and cognitive-behavioural psychotherapy in a randomly selected sample of the general public. Psychology and Psychotherapy: Theory, Research and Practice, 77(3), 297-307. https://doi.org/10.1348/1476083041839358

Buhrmester, M., Kwang, T., \& Gosling, S. D. (2011). Amazon’s Mechanical Turk: A new source of inexpensive, yet high-quality, data? Perspectives on Psychological Science, 6, 3-5. 
https://doi.org/10.1177/1745691610393980

Cain, C. K., Blouin, A. M., \& Barad, M. (2004). Adrenergic transmission facilitates extinction of conditional fear in mice. Learning and Memory, 11(2), 179-187. https://doi.org/10.1101/1m.71504

Casler, K., Bickel, L., \& Hackett, E. (2013). Separate but equal? A comparison of participants and data gathered via Amazon's MTurk, social media, and face-to-face behavioral testing. Computers in Human Behavior, 29(6), 2156-2160.

https://doi.org/10.1016/j.chb.2013.05.009

Choy, Y., Fyer, A. J., \& Lipsit, J. D. (2007). Treatment of specific phobia in adults. Clinical Psychology Review, 17(3), 266-286. https://doi.org/10.1016/j.cpr.2006.10.002

Crano, W. D., Brewer, M. B., \& Lac, A. (Eds.). (2014). Principles and methods of social research. New York: Routledge.

Craske, M. G. (2003). Origins of phobias and anxiety disorders: Why more women than men? Oxford, UK: Elsevier Ltd.

Craske, M. G., Kircanski, K., Zelikowsky, M., Mystkowski, J., Chowdhury, N., \& Baker, A. (2008). Optimizing inhibitory learning during exposure therapy. Behaviour Research and Therapy, 46(1), 5-27. https://doi.org/10.1016/j.brat.2007.10.003

Craske, M. G., Treanor, M., Conway, C. C., Zbozinek, T., \& Vervliet, B. (2014). Maximizing exposure therapy: An inhibitory learning approach. Behaviour Research and Therapy, 58, 10-23. https://doi.org/10.1016/j.brat.2014.04.006

Culver, N. C., Stoyanova, M., \& Craske, M. G. (2012). Emotional variability and sustained arousal during exposure. Journal of Behavior Therapy and Experimental Psychiatry, 43(2), 787-793. https://doi.org/10.1016/j.jbtep.2011.10.009 
Daflos, S., \& Whittal, M. L. (2012). Exposure therapy in OCD: Is there a need for adding cognitive elements? In P. Neudeck \& H.-U. Wittchen (Eds.), Exposure therapy: Rethinking the model-refining the method (pp. 335-350). https://doi.org/10.1007/978-1-4614-3342-2

Davis, T. E., Ollendick, T. H., \& Ost, L. G. (2012). Intensive One-Session Treatment of Specific Phobias. New York, NY: Springer. https://doi.org/10.1007/978-1-4614-3253-1

Deacon, B. J., \& Abramowitz, J. S. (2005). Patients' perceptions of pharmacological and cognitive-behavioral treatments for anxiety disorders. Behavior Therapy, 36(2), 139-145. https://doi.org/10.1016/S0005-7894(05)80062-0

Dooley, T. P. (2015). Treating anxiety with either beta blockers or antiemetic antimuscarinic drugs: A review. Mental Health in Family Medicine, 11, 89-99. Retrieved from https://www.researchgate.net/profile/Thomas_Dooley/publication/286926434_Treating_An xiety_with_either_Beta_Blockers_or_Antiemetic_Antimuscarinic_Drugs_A_Review/links/ 56701f9808ae0d8b0cc0d924/Treating-Anxiety-with-either-Beta-Blockers-or-AntiemeticAntimus

Farach, F. J., Pruitt, L. D., Jun, J. J., Jerud, A. B., Zoellner, L. A., \& Roy-Byrne, P. P. (2012). Pharmacological treatment of anxiety disorders: Current treatments and future directions. Journal of Anxiety Disorders, 26(8), 833-843. https://doi.org/10.1016/j.janxdis.2012.07.009

Faul, F., Erdfelder, E., Lang, A.-G., \& Buchner, A. (2007). G*Power 3: A flexible statistical power analysis program for the social, behavioral, and biomedical sciences. Behavior Research Methods, 39(2), 175-191. https://doi.org/10.3758/BF03193146

Foa, E. B., \& Kozak, M. J. (1986). Emotional processing of fear: Exposure to corrective information. Psychological Bulletin, 99(1), 20-35. https://doi.org/10.1037/00332909.99.1.20 
Frövenholt, J., Bragesjö, M., Clinton, D., \& Sandell, R. (2007). How do experiences of psychiatric care affect the perceived credibility of different forms of psychotherapy? Psychology and Psychotherapy: Theory, Research and Practice, 80(2), 205-215. https://doi.org/10.1348/147608306X116098

Glenn, D., Golinelli, D., Rose, R. D., Roy-Byrne, P., Stein, M. B., Sullivan, G., ... Craske, M. G. (2013). Who gets the most out of cognitive behavioral therapy for anxiety disorders? The role of treatment dose and patient engagement. Journal of Consulting and Clinical Psychology, 81(4), 639-649. https://doi.org/10.1037/a0033403

Groves, P. M., \& Thompson, R. F. (1970). Habituation: A dual-process theory. Psychological Review, 77(5), 419-450. https://doi.org/10.1037/h0029810

Heaton, L. J., Carlson, C. R., Smith, T. A., Baer, R. A., \& De Leeuw, R. (2007). Predicting anxiety during dental treatment using patients' self-reports: Less is more. Journal of the American Dental Association, 138(2), 188-195. https://doi.org/10.14219/jada.archive.2007.0135

Hellström, K., \& Öst, L. G. (1995). One-session therapist directed exposure vs two forms of manual directed self-exposure in the treatment of spider phobia. Behaviour Research and Therapy, 33(8), 959-965. https://doi.org/10.1016/0005-7967(95)00028-V

Herry, C., Ferraguti, F., Singewald, N., Letzkus, J. J., Ehrlich, I., \& Lüthi, A. (2010). Neuronal circuits of fear extinction. European Journal of Neuroscience, 31(4), 599-612. https://doi.org/10.1111/j.1460-9568.2010.07101.x

Huff, C., \& Tingley, D. (2015). "Who are these people?” Evaluating the demographic characteristics and political preferences of MTurk survey respondents. Research \& Politics, 2(3), 1-12. https://doi.org/10.1177/2053168015604648 
Ipser, J. C., Dewing, S., \& Stein, D. J. (2007). A systematic review of the quality of information on the treatment of anxiety disorders on the internet. Current Psychiatry Reports, 9(4), 303309. Retrieved from

http://shibboleth.ovid.com/secure/?T=JS\&CSC $=$ Y \&NEWS=N\&PAGE=fulltext\&D=med5\& $\mathrm{AN}=17880862 \% 5 \mathrm{Cnhttp}: / / \mathrm{sfx} . \mathrm{kcl} . \mathrm{ac} . \mathrm{uk} / \mathrm{kings}$ sid=OVID:medline\&id=pmid:\&id=doi:\&gen $\mathrm{re}=$ article $\&$ atitle $=\mathrm{A}+$ systematic + review + of + the + quality + of + information + on + the + treatment + of + anxiety + disord

Jaeger, J. A., Echiverri, A., Zoellner, L. A., Post, L., \& Feeny, N. C. (2009). Factors associated with choice of exposure therapy for PTSD. International Journal of Behavioral and Consultation Therapy, 5(3-4), 294-310. https://doi.org/10.1038/jid.2014.371

Johansson, R., Nyblom, A., Carlbring, P., Cuijpers, P., \& Andersson, G. (2013). Choosing between Internet-based psychodynamic versus cognitive behavioral therapy for depression: A pilot preference study. BMC Psychiatry, 13, 268. https://doi.org/10.1186/1471-244X-13268

Jöhren, P., Jackowski, J., Gängler, P., Sartory, G., \& Thom, A. (2000). Fear reduction in patients with dental treatment phobia. British Journal of Oral and Maxillofacial Surgery, 38(6), 612-616. https://doi.org/10.1054/bjom.2000.0531

Jones, J. A., Kressin, N. R., Miller, D. R., Orner, M. B., Garcia, R. I., \& Spiro, A. (2004). Comparison of patient-based oral health outcome measures. Quality of Life Research, 13(5), 975-985. https://doi.org/10.1023/B:QURE.0000025596.05281.d6

Jones, J. A., Spiro, A., Miller, D. R., Garcia, R. I., \& Kressin, N. R. (2002). Need for dental care in older veterans: Assessment of patient-based measures. Journal of the American Geriatrics Society, 50, 163-168. https://doi.org/10.1046/j.1532-5415.2002.50023.x 
Jung, T., \& Wickrama, K. A. (2008). An Introduction to Latent Class Growth Analysis and Growth Mixture Modeling. Social and Personality Psychology Compass, 2(1), 302-317. https://doi.org/10.1111/j.1751-9004.2007.00054.x

Kazantzis, N., Ford, C., Paganini, C., Dattilio, F. M., \& Farchione, D. (2017). Does patient reluctance towards exposure and psychologists' attitudes about evidence based practice influence treatment recommendations for panic disorder? An experimental investigation. Journal of Anxiety Disorders, 51, 1-10. https://doi.org/10.1016/j.janxdis.2017.03.001

Kessler, R. C., Berglund, P., Demler, O., Jin, R., Merikangas, K. R., \& Walters, E. E. (2005). Lifetime prevalence and age-of-onset distributions of DSM-IV disorders in the national comorbidity survey replication. Archives of General Psychiatry, 62(6), 593. https://doi.org/10.1001/archpsyc.62.6.593

Kleinknecht, R. A., Klepac, R. K., \& Alexander, L. D. (1973). Origins and characteristics of fear of dentistry. Journal of the American Dental Association, 86(4), 842-848. https://doi.org/10.14219/jada.archive.1973.0165

Lang, A. J., \& Craske, M. G. (2000). Manipulations of exposure-based therapy to reduce return of fear: A replication. Behaviour Research and Therapy, 38(1), 1-12. https://doi.org/10.1016/S0005-7967(99)00031-5

Lang, P. J. (1971). The application of psychophysiological methods to the study of psychotherapy and behaviour modification. In A. E. Bergin \& S. L. Garfield (Eds.), Handbook of psychotherapy and behavior change (pp. 75-125). New York: John Wiley \& Sons.

Lindhiem, O., Bennett, C. B., Trentacosta, C. J., \& McLear, C. (2014). Client preferences affect treatment satisfaction, completion, and clinical outcome: A meta-analysis. Clinical 
Psychology Review, 34(6), 506-517. https://doi.org/10.1016/j.cpr.2014.06.002

Liu, H. H., Milgrom, P., \& Fiset, L. (1991). Effect of a beta-adrenergic blocking agent on dental anxiety. Journal of Dental Research, 70(9), 1306-1308.

https://doi.org/10.1177/00220345910700091401

Mason, W., \& Suri, S. (2012). Conducting behavioral research on Amazon's Mechanical Turk. Behavior Research Methods, 44, 1-23. https://doi.org/10.3758/s13428-011-0124-6

Masters, J. C., Burish, T. G., Hollon, S. D., \& Rimm, D. C. (Eds.). (1987). Behavior therapy techniques and empirical findings (3rd ed.). New York: Harcourt Brace Joanovich, Inc.

McGlynn, F. D., McNeil, D. W., Gallagher, S. L., \& Vrana, S. R. (1987). Factor structure, stability, and internal consistency of the Dental Fear Survey. Behavioral Assessment, 9(1), $57-66$.

McHugh, R., \& Whitton, S. (2013). Patient preference for psychological vs. pharmacological treatment of psychiatric disorders: A meta-analytic review. Jounral of Clinical Psychiatry, 74(6), 595-602. https://doi.org/10.4088/JCP.12r07757.Patient

McNeil, D. W. (2011). Even the most sophisticated oral health interventions and technologies are of no help unless people accept and use them. Journal of Public Health Dentistry, 71, S81-S82. https://doi.org/10.1111/j.1752-7325.2011.00232.x

McNeil, D. W. (2019). Using digital technology devices in the treatment of dental care-related anxiety and fear. Journal of Dental Research, 98, A-0355. [Abstract].

McNeil, D. W., \& Kyle, B. N. (2017). Exposure therapy for anxiety, fear, and trauma. In S. Cormier, P. S. Nurius, \& C. J. Osborn (Eds.), Interviewing and change strategies for helpers (8th ed., pp. 491-527). Boston, MA: Cengage Learning.

McNeil, D. W., \& Randall, C. L. (2014). Dental fear and anxiety associated with oral health care: 
Conceptual and clinical issues. In D. I. Mostofsky \& F. Fortune (Eds.), Behavioral dentistry (2nd ed., pp. 165-192). Ames, Iowa: Wiley/Blackwell.

McPherson, K., Britton, A. R., \& Wennberg, J. E. (1997). Are randomized controlled trials controlled? Patient preferences and unblind trials. Journal of the Royal Society of Medicine, 90(12), 652-656. Retrieved from

http://www.pubmedcentral.nih.gov/articlerender.fcgi?artid=1296732\&tool=pmcentrez\&ren dertype $=$ abstract

Michelson, L., Mavissakalian, M., Marchione, K., Dancu, C., \& Greenwald, M. (1986). The role of self-directed in vivo exposure in cognitive, behavioral, and psychophysiological treatments of agoraphobia. Behavior Therapy, 17(2), 91-108. https://doi.org/10.1016/S0005-7894(86)80078-8

Mohlman, J. (2012). A community based survey of older adults' preferences for treatment of anxiety. Psychology and Aging, 27(4), 1182-1190. https://doi.org/10.1037/a0023126

Myers, K. M., \& Davis, M. (2007). Mechanisms of fear extinction. Molecular Psychiatry, 12(2), 120-150. https://doi.org/10.1038/sj.mp.4001939

NHANES. (2016). National Health and Nutrition Examination Survey. Retrieved from https://wwwn.cdc.gov/nchs/nhanes/ContinuousNhanes/Default.aspx?BeginYear=2015

O’Donohue, W. T., \& Fisher, J. E. (Eds.). (2009). General principles and empirically supported techniques of cognitive behavior therapy. Hoboken, New Jersey: John Wiley \& Sons, Inc.

Pavlov, I. P. (1927). Conditioned reflexes: An investigation of the physiological activity of the cerebral cortex. Oxford, UK: Oxford University Press.

Peer, E., Vosgerau, J., \& Acquisti, A. (2014). Reputation as a sufficient condition for data quality on Amazon Mechanical Turk. Behavior Research Methods, 46(4), 1023-1031. 
https://doi.org/10.3758/s13428-013-0434-y

Rachman, S. (1980). Emotional processing. Behaviour Research and Therapy, 18, 51-60. https://doi.org/10.1016/0005-7967(80)90069-8

Richard, D. C. S., \& Gloster, A. T. (2007). Exposure therapy has a public relations problem. In Handbook of exposure therapies (pp. 409-425). https://doi.org/10.1016/B978-0125874212/50019-3

Roest, A. M., de Jonge, P., Williams, C. D., de Vries, Y. A., Schoevers, R. A., \& Turner, E. H. (2015). ReportingbBias in clinical trials investigating the efficacy of second-generation antidepressants in the treatment of anxiety disorders: A report of 2 meta-analyses. JAMA Psychiatry, 72(5), 500-510. https://doi.org/10.1001/jamapsychiatry.2015.15

Rowe, M. K., \& Craske, M. G. (1998). Effects of varied-stimulus exposure training on fear reduction and return of fear. Behaviour Research and Therapy, 36(7-8), 719-734. https://doi.org/10.1016/S0005-7967(97)10017-1

Schneider, A. J., Mataix-Cols, D., Marks, I. M., \& Bachofen, M. (2005). Internet-guided selfhelp with or without exposure therapy for phobic and panic disorders. Psychotherapy and Psychosomatics, 74(3), 154-164. https://doi.org/10.1159/000084000

Simons, J. S., \& Gaher, R. M. (2005). The distress tolerance scale: Development and validation of a self-report measure. Motivation and Emotion, 29(2), 83-102. https://doi.org/10.1007/s11031-005-7955-3

Simpson, H. B., Maher, M. J., Wang, Y., Bao, Y., Foa, E. B., \& Franklin, M. (2011). Patient adherence predicts outcome from cognitive behavioral therapy in obsessive-compulsive disorder. Journal of Consulting and Clinical Psychology, 79(2), 247-252. https://doi.org/10.1037/a0022659 
Smith, M., Robinson, L., \& Segal, J. (2017). Anxiety medications: What you need to know about benzodiazepines \& other anxiety drugs. Retrieved January 1, 2017, from https://www.helpguide.org/articles/anxiety/anxiety-medication.htm

Smith, T. a, \& Heaton, L. J. (2003). Fear of dental care: are we making any progress? Journal of the American Dental Association (1939), 134(8), 1101-1108. https://doi.org/10.14219/jada.archive.2003.0326

Swift, J. K., \& Callahan, J. L. (2009). The impact of client treatment preferences on outcome: A meta-analysis. Journal of Clinical Psychology, 65(4), 368-381. https://doi.org/10.1002/jclp.20553

Swift, J. K., Callahan, J. L., Ivanovic, M., \& Kominiak, N. (2013). Further examination of the psychotherapy preference effect: A meta-regression analysis. Journal of Psychotherapy Integration, 23(2), 134-145. https://doi.org/10.1037/a0031423

Swift, J. K., Callahan, J. L., \& Vollmer, B. M. (2011). Preferences. Journal of Clinical Psychology, 67(2), 155-165. https://doi.org/10.1002/jclp.20759

Tarrier, N., Liversidge, T., \& Gregg, L. (2006). The acceptability and preference for the psychological treatment of PTSD. Behaviour Research and Therapy, 44(11), 1643-1656. https://doi.org/10.1016/j.brat.2005.11.012

Taylor, S., Abramowitz, J. S., \& McKay, D. (2012). Non-adherence and non-response in the treatment of anxiety disorders. Journal of Anxiety Disorders, 26(5), 583-589. https://doi.org/10.1016/j.janxdis.2012.02.010

Vujanovic, A. A., Hart, A. S., Potter, C. M., Berenz, E. C., Niles, B., \& Bernstein, A. (2013). Main and interactive effects of distress tolerance and negative affect intensity in relation to PTSD symptoms among trauma-exposed adults. Journal of Psychopathology and 
Behavioral Assessment, 35(2), 235-243. https://doi.org/10.1007/s10862-012-9325-2

Wang, J., \& Wang, X. (2012). Structural equation modeling: Applications using Mplus. West Sussex, UK: Higher Education Press.

Wang, P. S., Lane, M., Olfson, M., Pincus, H. A., Wells, K. B., \& Kessler, R. C. (2005). Twelvemonth use of mental health services in the United States. Archives of General Psychiatry, 62(6), 629-640. https://doi.org/10.1001/archpsyc.62.6.629

Wheaton, M. G., Carpenter, J. K., Kalanthroff, E., Foa, E. B., \& Simpson, H. B. (2016). Augmenting SRIs for Obsessive-Compulsive Disorder: Patient preference for Risperidone does not limit effectiveness of exposure and ritual prevention. Psychotherapy and Psychosomatics, 85(5), 314-316. https://doi.org/10.1159/000445356

Wheaton, M. G., Galfalvy, H., Steinman, S. A., Wall, M. M., Foa, E. B., \& Simpson, H. B. (2016). Patient adherence and treatment outcome with exposure and response prevention for OCD: Which components of adherence matter and who becomes well? Behaviour Research and Therapy, 85, 6-12. https://doi.org/10.1016/j.brat.2016.07.010

Wilhelm, F. H., \& Roth, W. T. (1997). Acute and delayed effects of alprazolam on flight phobics during exposure. Behaviour Research and Therapy, 35(9), 831-841. https://doi.org/10.1016/S0005-7967(97)00033-8

Willumsen, T., Vassend, O., \& Hoffart, A. (2001). A comparison of cognitive therapy, applied relaxation, and nitrous oxide sedation in the treatment of dental fear. Acta Odontologica, 59(5), 290-296. Retrieved from http://informahealthcare.com/doi/abs/10.1080/000163501750541156

Wolitzky-Taylor, K. B., Horowitz, J. D., Powers, M. B., \& Telch, M. J. (2008). Psychological approaches in the treatment of specific phobias: A meta-analysis. Clinical Psychology 
Review, 28(6), 1021-1037. https://doi.org/10.1016/j.cpr.2008.02.007

Wolpe, J. (1958). Psychotherapy by reciprocal inhibition. Standford, CA: Stanford University Press.

Wolpe, J. (1973). The practice of behavior therapy. New York: Pergamon Press.

Wright, W. G., Jones, J. A., Spiro, A., Rich, S. E., \& Kressin, N. R. (2009). Use of patient selfreport oral health outcome measures in assessment of dental treatment outcomes. Journal of Public Health Dentistry, 69(2), 95-103. https://doi.org/10.1111/j.1752-7325.2008.00106.x

Yaghoobi, S., Mahmoodiyeh, B., Khezri, M. B., Hashemian, S. M., \& Fard, A. J. (2015). Orally administration of propranolol, lorazepam, and combination of propranolol/lorazepam, and reducing anxiety before surgery. Archives of Critical Care Medicine, 1(2), 1-5. https://doi.org/10.17795/accm-3426 


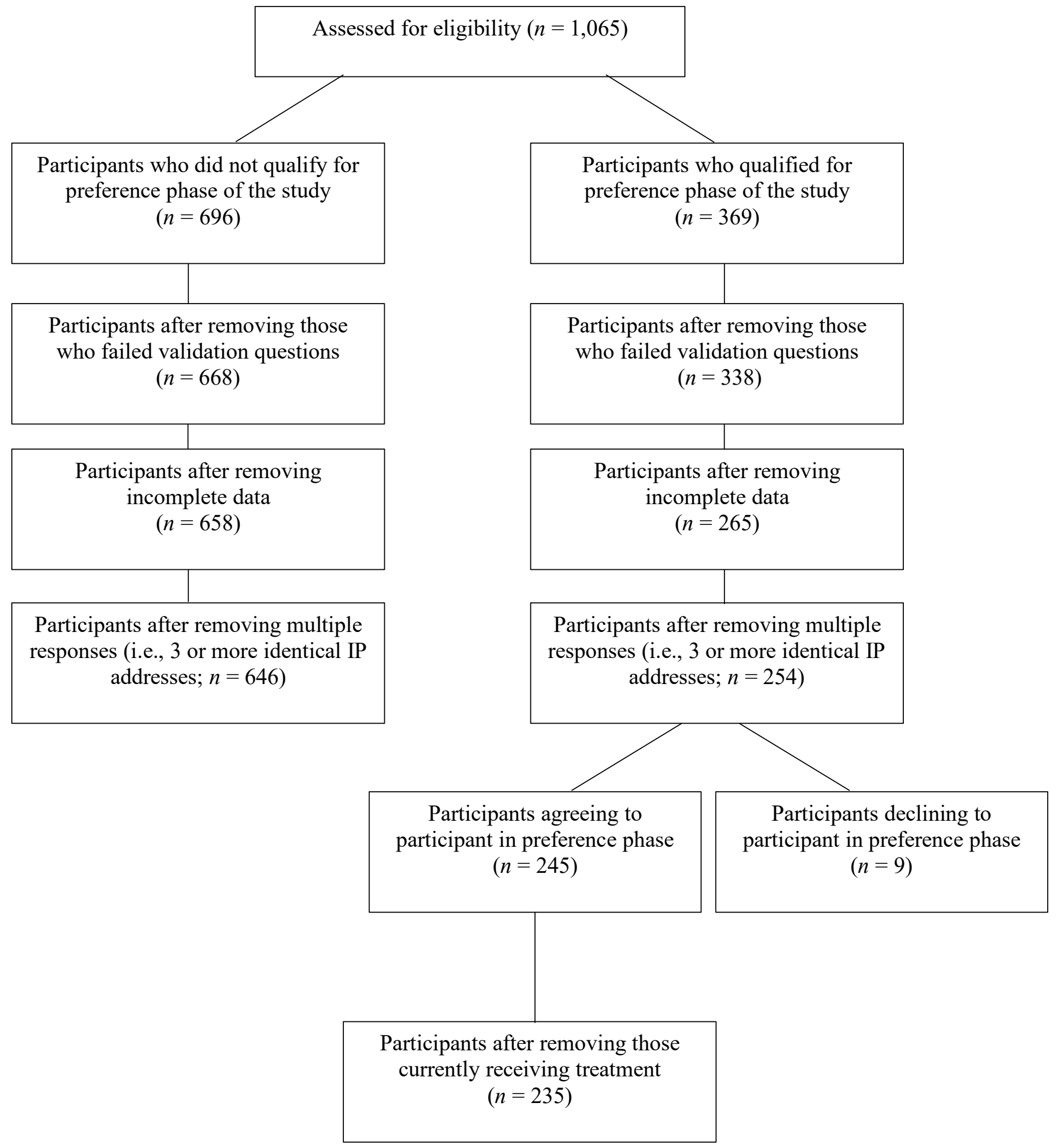

Figure 1. Participant Flow for Inclusion in the Study 


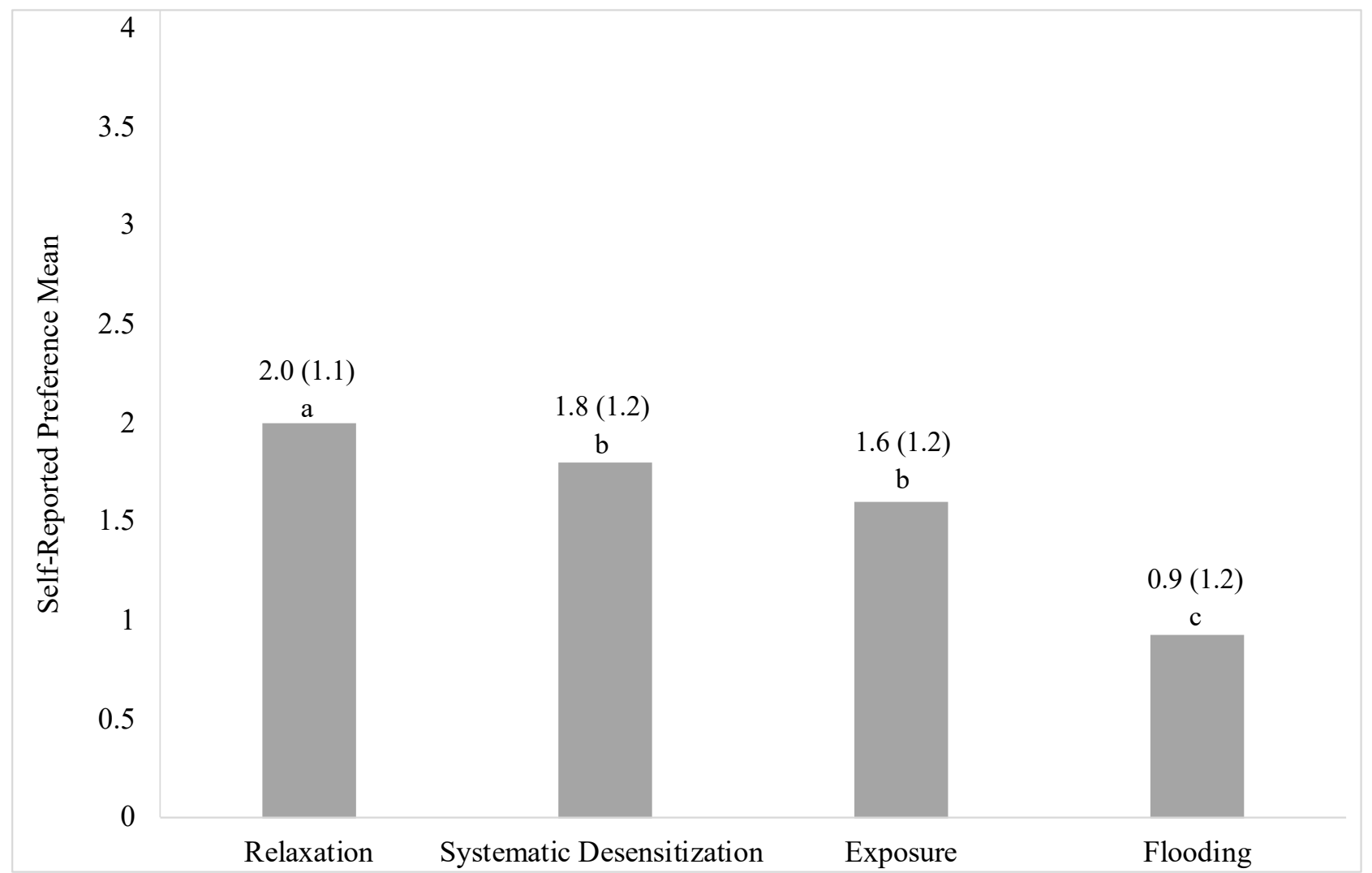

Figure 2. Participant Preference for Various Types of Treatments. Columns that do not share a common superscript differ at $p<.05$. 


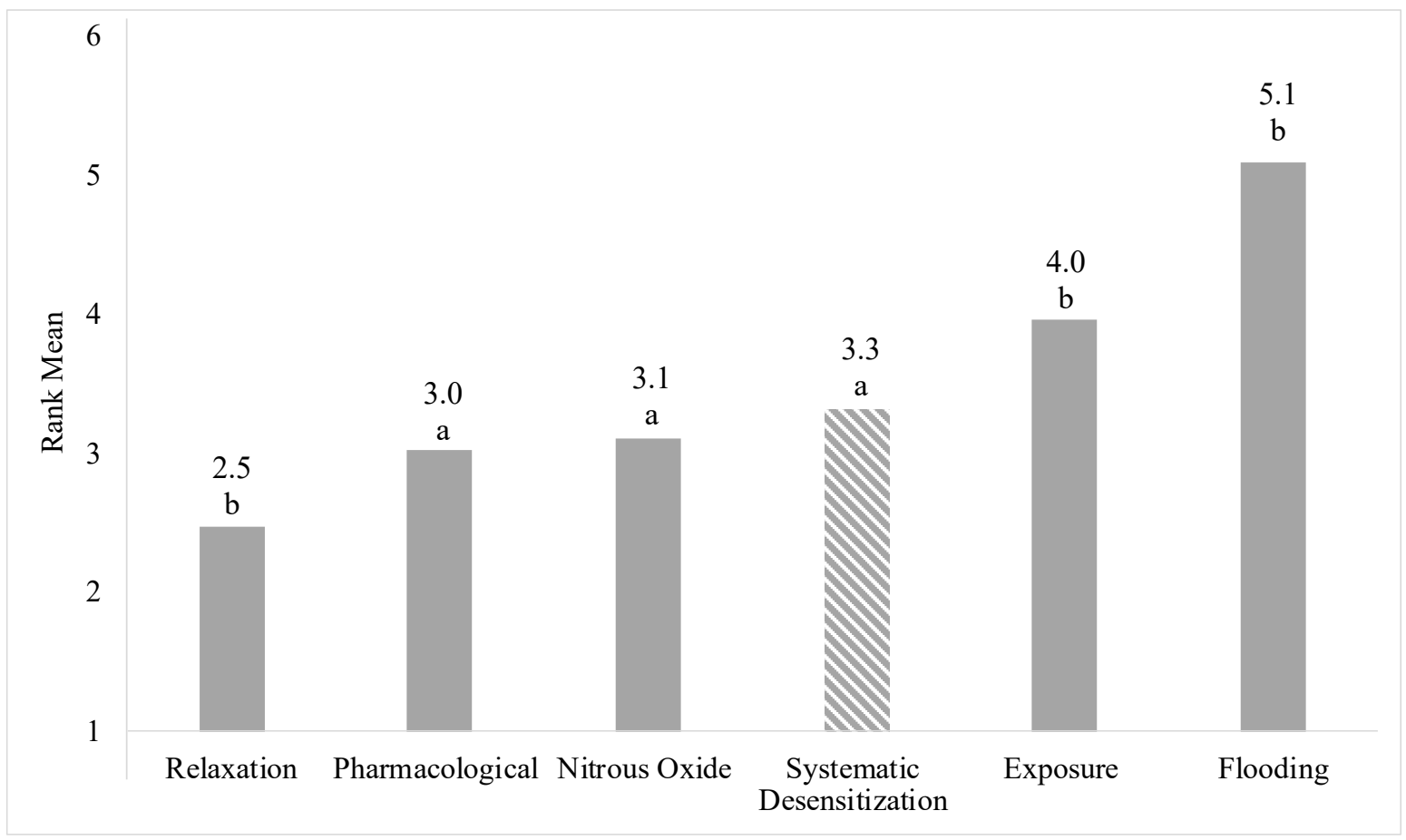

Figure 3. Participant ranked preference for types of treatments. Planned post-hoc contrasts via Wilcoxon signed-rank test comparing systematic desensitization and the other options were conducted with a Bonferroni correction (i.e., $p<0.01$ ). Columns that do not share a common superscript with Systematic Desensitization differ at $p<.01$. Lower ranks indicate a higher preference for that treatment; for example, a score of one would indicate a first choice option and a score of 6 would indicate last choice option. 
5

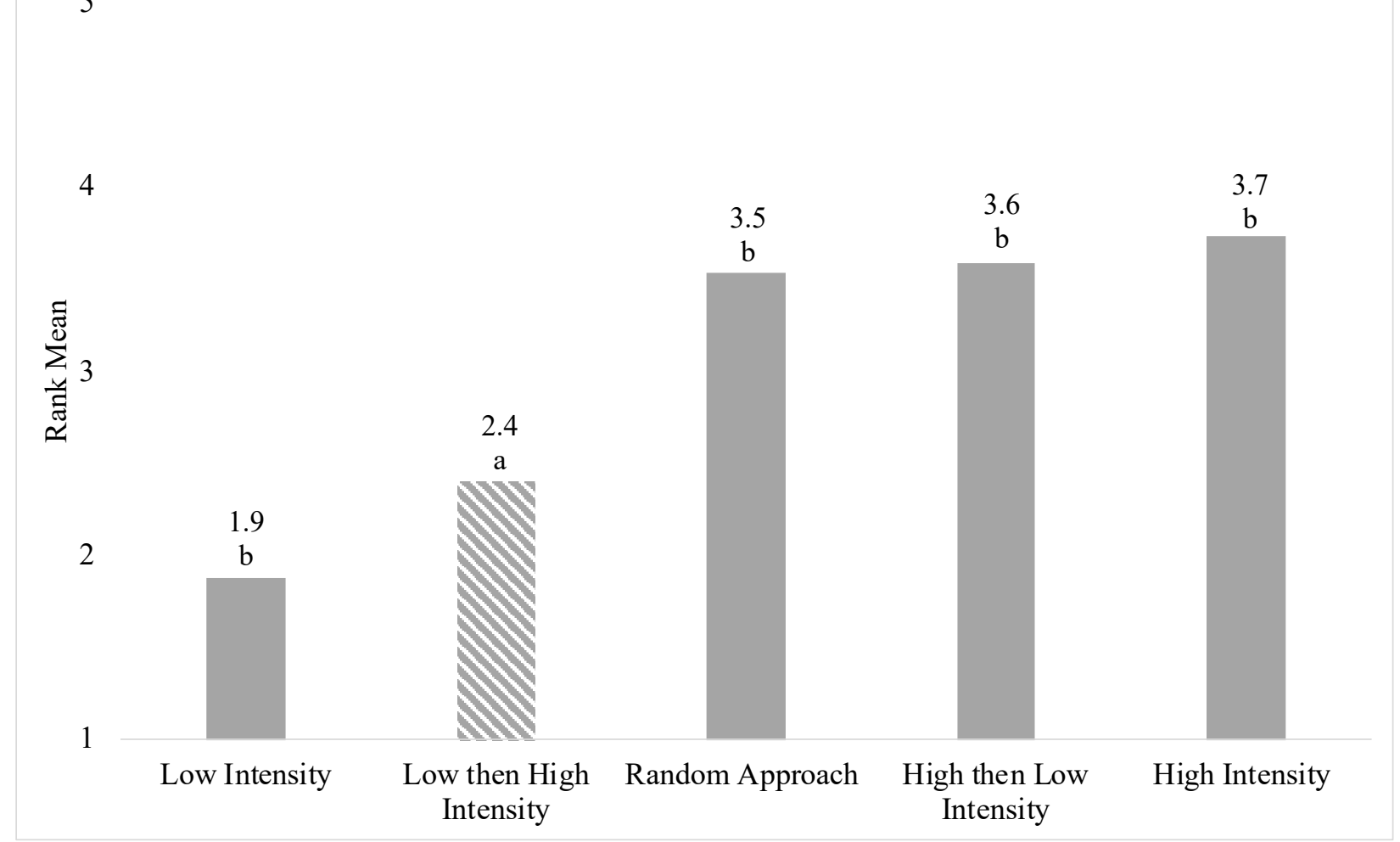

Figure 4. Graph of Participant Ranked Preference for Presentation of Exposure Stimuli. Planned post hoc contrasts via a Wilcoxon signed-rank test comparing gradual accelerating approach (i.e., Low then High Intensity) and the other options was conducted with a Bonferroni correction (i.e., $p<0.0125$ ). Columns that do not share a common superscript with Low then High Intensity differ at $p<.0125$. Lower ranks indicate a higher preference for that treatment; for example, a score of one would indicate a first choice option and a score of 6 would indicate last choice option. 


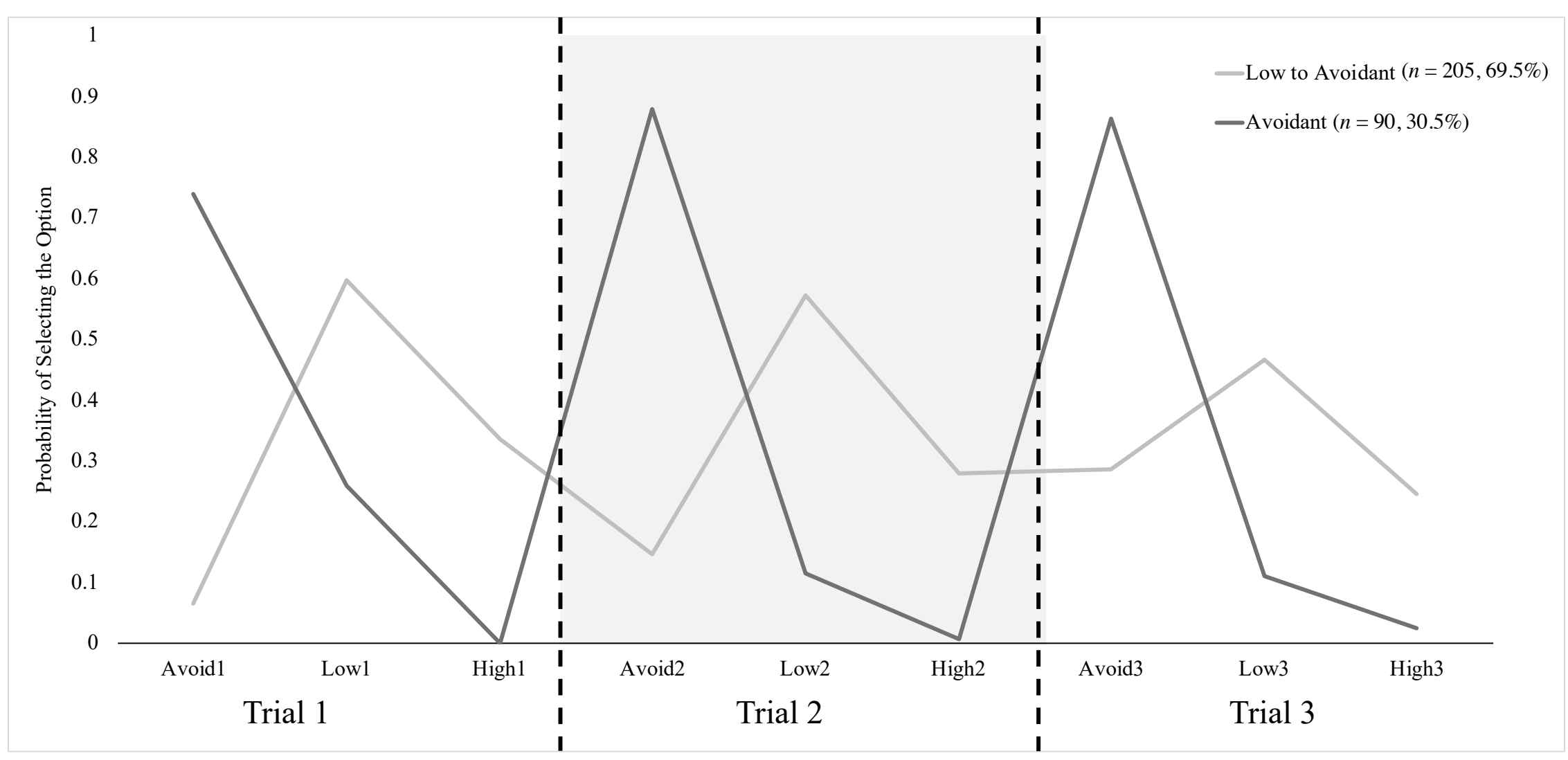

Figure 5. Latent Class Analysis for Videos Watched over the Three Trials. The y-axis is the probability (e.g., likelihood) of selecting the different video types (i.e., black screen, how intensity, or high intensity) based on which group participants were identified. Avoid1, Avoid2, and Avoid3 is the black screen option for the three trials. The Low1, Low2, and Low3 is the low intensity option for the three trials. The High1, High2, and High3 is the high intensity option for the three trials. 
Table 1

Anxiety Ratings for Exposure Videos Considered for Inclusion in Present Study

\begin{tabular}{|c|c|c|c|c|}
\hline & Mean (SD) & $\begin{array}{c}\text { Video } \\
\text { Length }(\mathrm{Sec})\end{array}$ & $\begin{array}{l}\text { Number of } \\
\text { Participants Who } \\
\text { Watched the Video } \\
\text { in the Prior Study }\end{array}$ & Video Content \\
\hline *Video 1 & $43.3(22.1)$ & 120 & 29 & $\begin{array}{l}\text { Patient walking into a dental clinic. Then the patient had a short } \\
\text { conversation with the dental hygienist. Finally, the dental hygienist } \\
\text { performed an examination and prophylaxis. }\end{array}$ \\
\hline Video 3 & $47.7(24.6)$ & 28 & 29 & Patient receiving a teeth cleaning. \\
\hline Video 4 & $54.2(18.6)$ & 120 & 29 & Dentist performing a scaling on a patient's teeth. \\
\hline Video 7 & $61.2(19.8)$ & 120 & 28 & Dentist drilling into a tooth of a patient. \\
\hline Video 8 & $63.2(19.4)$ & 120 & 24 & A close-up view of a tooth being drilled. \\
\hline Video 9 & $61.4(19.0)$ & 120 & 14 & Patient having a tooth removed. \\
\hline Video 10 & $38.5(16.4)$ & 120 & 8 & Patient receiving a crown on a tooth. \\
\hline
\end{tabular}

Note. ${ }^{*}$ Videos selected for the current study. Not all participants viewed all 10 videos. SD $=$ standard deviation. 
Table 2

Sample Demographic Characteristics and Tests for Possible Differences

\begin{tabular}{|c|c|c|c|c|c|}
\hline & \multicolumn{3}{|c|}{ Participants Mean $(S D)$} & \multirow[b]{2}{*}{$p$-value } & \multirow[b]{2}{*}{ Combined } \\
\hline & Screen & Preference & Statistic & & \\
\hline Age & $38.4(12.5)$ & $39.5(12)$ & $t(877)=-1.2$ & $p=.241$ & $38.7(12.3)$ \\
\hline \multirow[t]{2}{*}{ Education } & $15.5(2.3)$ & $15.2(2.1)$ & $t(877)=1.9$ & $p=.053$ & $15.5(2.2)$ \\
\hline & \multicolumn{2}{|c|}{$N(\%)$} & & & $N(\%)$ \\
\hline \multirow{6}{*}{$\begin{array}{r}\text { Female } \\
\text { Male } \\
\text { Statistic } \\
p \text {-value }\end{array}$} & & & $\chi^{2}=27.2$ & $p<.001$ & \\
\hline & $309(47.8 \%)$ & $159(67.7 \%)$ & & & $468(53.1 \%)$ \\
\hline & $337(52.2 \%)$ & $76(32.3 \%)$ & & & $413(46.9 \%)$ \\
\hline & $\chi^{2}=1.2$ & $\chi^{2}=29.3$ & & & $\chi^{2}=3.4$ \\
\hline & $p=.27$ & $p<.001$ & & & $p=.064$ \\
\hline & \multicolumn{2}{|c|}{$N(\%)$} & & & $N(\%)$ \\
\hline \multicolumn{6}{|l|}{ Race/Ethnicity* } \\
\hline White & $513(79.4 \%)$ & $184(78.3 \%)$ & $\chi^{2}=1.2$ & $p=.72$ & $697(79.1 \%)$ \\
\hline $\begin{array}{r}\text { Black/African } \\
\text { American }\end{array}$ & $63(9.7 \%)$ & $47(16.8 \%)$ & $\chi^{2}=1.5$ & $p=.22$ & $87(9.9 \%)$ \\
\hline Latinx/Hispanic & $36(5.5 \%)$ & $14(5 \%)$ & $\chi^{2}=0.6$ & $p=.44$ & $46(5.2 \%)$ \\
\hline Asian & $51(7.8 \%)$ & $22(7.9 \%)$ & $\chi^{2}=.1$ & $p=.75$ & $68(7.7 \%)$ \\
\hline \multirow[t]{2}{*}{ Native American } & $12(1.8 \%)$ & $1(0.4 \%)$ & $\chi^{2}=4.4$ & $p=.035$ & $12(1.4 \%)$ \\
\hline & \multicolumn{3}{|c|}{ Mean $(S D)$} & & Mean $(S D)$ \\
\hline DFS Total & $40.2(15.8)$ & $75.8(15.6)$ & $t(447.52)=-31.4$ & $p<.001$ & $49.7(22.1)$ \\
\hline DFS Item 20 & $2.0(0.8)$ & $4.4(0.5)$ & $t(670.53)=-52.7$ & $p<.001$ & $2.7(1.3)$ \\
\hline
\end{tabular}

Note. *Percentages equal more than $100 \%$ due to participants choosing more than one race/ethnicity. $\mathrm{SD}=$ standard deviation. $N=$ number. Chi-Square analyses were conducted for sex differences among and between both the screening and preference phase participants. ChiSquare analyses were conducted for race/ethnicity differences between the screening and preference phase participants. 
Table 3

Fit Indices for Latent Class Analysis

\begin{tabular}{cccccccc}
\hline & AIC & BIC & ABIC & Entropy & LMR LR & ALMR LR & BLRT \\
\cline { 2 - 6 } 1 class & 1855.715 & 1877.837 & 1858.809 & - & - & - \\
2 class & $\mathbf{1 7 2 9 . 2 3 9}$ & $\mathbf{1 7 7 7 . 1 6 9}$ & $\mathbf{1 7 3 5 . 9 4 3}$ & 0.765 & $\boldsymbol{p}<.001$ & $\boldsymbol{p}<.001 \quad p<.001$ \\
3 class & $\mathbf{1 6 7 7 . 3 2 2}$ & $\mathbf{1 7 5 1 . 0 6 2}$ & $\mathbf{1 6 8 7 . 6 3 6}$ & 0.838 & $p=.62$ & $p=.63 \quad p<.001$ \\
\hline
\end{tabular}

Note. $\mathrm{AIC}=$ Akaike information criterion. $\mathrm{BIC}=$ Bayesian information criterion. $\mathrm{ABIC}=$ adjusted Bayesian information criterion. $\mathrm{LMR} \mathrm{LR}=\mathrm{Lo}-$ Mendell-Rubin likelihood ratio test. ALMR LR = adjusted Lo-Mendell-Rubin likelihood ratio test. BLRT = bootstrapped likelihood ratio test. 


\section{Appendix A \\ Exposure Videos Considered for Inclusion in Present Study}

1. Patient walking into a dental clinic. Then the patient had a short conversation with the dental hygienist. Finally, the dental hygienist performed an examination and prophylaxis.

2. Patient is lying supine in a dental chair being examined by a dentist.

3. Patient receiving a teeth cleaning.

4. Dentist performing a scaling on a patient's teeth.

5. Patient lying supine in a dental chair receiving injections.

6. View of an open mouth while a root planning is being performed.

7. Dentist drilling into a tooth of a patient.

8. A close-up view of a tooth being drilled.

9. Patient having a tooth removed.

10. Patient receiving a crown on a tooth. 


\title{
Appendix B \\ Descriptions of Treatment Options from the APA Dictionary of Psychology
}

(American Psychological Association, 2015)

\begin{abstract}
"Systematic Desensitization: a form of behavior therapy in which counterconditioning is used to reduce anxiety associated with a particular stimulus. It involves the following stages: (a) The client is trained in deep-muscle relaxation; (b) various anxiety-provoking situations related to a particular problem, such as fear of death or a specific phobia, are listed in order from weakest to strongest; and (c) each of these situations is presented in imagination or in reality, beginning with the weakest, while the client practices muscle relaxation. Since the muscle relaxation is incompatible with the anxiety, the client gradually responds less to the anxiety-provoking situations."
\end{abstract}

"Relaxation: a technique in which the individual is trained to relax the entire body by becoming aware of tensions in various muscle groups and then relaxing one muscle group at a time. In some cases, the individual consciously tenses specific muscles or muscle groups and then releases tension to achieve relaxation throughout the body. Relaxation technique [is] any therapeutic technique to induce relaxation and reduce stress. Also called relaxation training. Relaxation therapy [is the] use of muscle-relaxation techniques to aid in the treatment of emotional tension. Also called therapeutic relaxation."

"Exposure therapy: a form of behavior therapy that is effective in treating anxiety disorders. It involves systematic and repeated confrontation with a feared stimulus, either in vivo (live) or in the imagination. It works by (a) implosive therapy, habituation, in which repeated exposure reduces anxiety over time by a process of extinction; (b) disconfirming fearful predictions; and (c) increasing feelings of self-efficacy and mastery. In vivo exposure [is] a type of exposure therapy, generally used for treating individuals with phobias, obsessive compulsive disorder, and other anxiety disorders, in which the client directly experiences anxiety-provoking situations or stimuli in real-world conditions. For example, a client who fears flying could be accompanied by a therapist to the airport to simulate boarding a plane while practicing anxiety-decreasing techniques, such as deep breathing. Imaginal exposure [is] a type of exposure therapy used for treating individuals with anxiety disorders (e.g., phobias, obsessive-compulsive disorder, posttraumatic stress disorder). Vivid imagery evoked through speech is used by the therapist to expose the client mentally to an anxiety evoking stimulus."

"Flooding: a technique in behavior therapy in which the individual is exposed directly to a maximum-intensity anxiety-producing situation or stimulus, either described or real, without any attempt made to lessen or avoid anxiety or fear during the exposure. An individual with claustrophobia, for example, might be asked to spend extended periods of time in a small room. Flooding techniques aim to diminish or extinguish the undesired response to a feared situation or stimulus and are used primarily in the treatment of individuals with phobias and similar disorders." 


\section{Appendix C}

\section{Demographic and General Dental Information Questionnaire}

1. What is your sex?
a. Male
b. Female

2. What is your age?

a. years

3. What is your race/ethnicity? Select all that Apply:
a. White/Caucasian
b. Black/African American
c. Hispanic
d. Asian
e. Indian or Alaskan Native
f. Other:

4. What is your marital status?
a. Single
b. Separated
c. Married
d. Divorced
e. Live-in partner
f. Widowed

5. Number of years of education? (For example, High School Diploma $=12$ years, College Degree $=16$ years)
a. years

6. What is your job or occupation?

a.

7. What is your current job or occupation status?
a. Working full time
b. Working part time
c. Looking for work - unemployed
d. Retired
e. Disabled - unable to work

8. How do you get to dental appointments?
a. Have a car/truck/vehicle that I primarily or solely use
b. Have a car/truck/vehicle that I share with a spouse/partner
c. Borrow a car/truck/vehicle
d. Have a family member bring me 
e. Have a friend bring me

f. Have a social services agency bring me

g. Other:

9. For the vehicle that gets you to dental appointments, how reliably does it run?

Very Unreliable

0

1
2
Very Reliable

4

10. What factors make it difficult for you to schedule or attend dental care appointments? (circle or list all that apply)
a. Hard to get away from work
b. Transportation hard to arrange
c. Not covered by insurance
d. Other:

11. How long since you last saw a dentist?
a. Within the last 6 months
b. 6 months -1 year
c. $1-2$ years
d. $2-5$ years
e. $5-10$ years
f. More than 10 years
g. Never saw a dentist

12. When you go to the dentist, what typically gets you to go?
a. Regular cleaning and exam
b. Pain
c. Seeing a cavity or another problem in my mouth
d. Other:

13. Do you presently have any dental pain?

No Pain

0

1

2

3

Severe Pain

4

14. Have you had any prior psychological treatment?
a. Yes
b. No

15. If you received previous psychological treatment, what were you treated for? (if this does not apply to you please respond with N/A)
a.
b. When did you start treatment?
c. When did you end treatment?
d. Are you currently in treatment?

16. Do you have any extreme fears or phobia? If so, please list. 
a. Yes

b. No

17. Are you currently taking any medications for mental health issues? If so, please list.
a. Yes

b. No

18. Have you ever taken any medications for mental health issues? If so, please list.

a. Yes

b. No

19. Have you ever received treatment for dental fear? If so, please list treatment(s).

a. Yes

b. No

20. When did you start treatment for your dental fear?

a.

b. Does not apply

21. When did you end treatment for your dental fear?

a.

b. Does not apply

22. Are you currently in treatment for your dental fear?
a. Yes
b. No
c. Does not apply

23. How often do you take medications for fear/anxiety when attending a dental visit?
a. Every time
b. Almost every time
c. More than half of the time
d. Less than half of the time
e. Rarely
f. Never
g. I have never gone to the dentist

24. How often do you use nitrous oxide for fear/anxiety when attending a dental visit?
a. Every time
b. Almost every time
c. More than half of the time
d. Less than half of the time
e. Rarely
f. Never
g. I have never gone to the dentist 


\section{Appendix D}

\section{Dental Fear Survey}

INSTRUCTIONS: The items in this questionnaire refer to various situations, feelings, and reactions related to dental work. Please rate your feeling or reaction on these items by using the following scales. Fill in the appropriate circle which most closely corresponds to your reaction.

\begin{tabular}{|c|c|c|c|c|c|}
\hline & Never & $\begin{array}{c}\text { Once or } \\
\text { twice }\end{array}$ & $\begin{array}{l}\text { A few } \\
\text { times }\end{array}$ & Often & $\begin{array}{c}\text { Nearly } \\
\text { every time }\end{array}$ \\
\hline $\begin{array}{l}\text { Has fear of dental work ever caused you } \\
\text { to put off making an appointment? }\end{array}$ & 1 & 2 & 3 & 4 & 5 \\
\hline $\begin{array}{l}\text { Has fear of dental work ever caused you } \\
\text { to cancel or not appear for an } \\
\text { appointment? }\end{array}$ & 1 & 2 & 3 & 4 & 5 \\
\hline
\end{tabular}

When having dental work done:

$\begin{array}{lccccc} & \text { Not At All } & \text { A little } & \text { Somewhat } & \text { Much } & \text { Very much } \\ \text { 3. My muscles become tense... } & 1 & 2 & 3 & 4 & 5 \\ \text { 4. My breathing rate increases... } & 1 & 2 & 3 & 4 & 5 \\ \text { 5. I perspire... } & 1 & 2 & 3 & 4 & 5 \\ \begin{array}{l}\text { 6. I feel nauseated and sick to my } \\ \quad \text { stomach... }\end{array} & 1 & 2 & 3 & 4 & 5 \\ \text { 7. My heart beats faster... } & 1 & 2 & 3 & 4 & 5\end{array}$

Following is a list of things, and situations that many people mention as being somewhat anxiety or fear producing. Please rate how much fear, anxiety, or unpleasantness each of them causes you. (If it helps, try to imagine yourself in each of these situations and describe what your common reaction is.)

8. Making an appointment for dentistry.

$\begin{array}{ccccc}\begin{array}{c}\text { Not At } \\ \text { All }\end{array} & \begin{array}{c}\text { A } \\ \text { little }\end{array} & \text { Somewhat } & \text { Much } & \begin{array}{c}\text { Very } \\ \text { much }\end{array} \\ 1 & 2 & 3 & 4 & 5 \\ 1 & 2 & 3 & 4 & 5 \\ 1 & 2 & 3 & 4 & 5 \\ 1 & 2 & 3 & 4 & 5 \\ 1 & 2 & 3 & 4 & 5 \\ 1 & 2 & 3 & 4 & 5 \\ 1 & 2 & 3 & 4 & 5 \\ 1 & 2 & 3 & 4 & 5 \\ 1 & 2 & 3 & 4 & 5 \\ 1 & 2 & 3 & 4 & 5 \\ 1 & 2 & 3 & 4 & 5 \\ 1 & 2 & 3 & 4 & 5 \\ 1 & 2 & 3 & 4 & 5\end{array}$

9. Approaching the dentist's office.

10. Sitting in the waiting room.

11. Being seated in the dental chair.

12. The smell of the dentist's office.

13. Seeing the dentist walk in.

14. Seeing the anesthetic needle.

15. Feeling the needle injected.

16. Seeing the drill.

17. Hearing the drill.

18. Feeling the vibrations of the drill.

19. Having your teeth cleaned.

20. All things considered, how fearful are you of having dental work done? 
Appendix E

Treatment Preference

What is your level of preference for the proposed treatment that you just read about/watched?

Low Preference

0

1

2

3

High Preference

4 


\section{Appendix F \\ Treatment Preference Ranking}

Please rank the following ways to manage your dental fear/anxiety by your preference:
a. Medication
b. Systematic desensitization
c. Relaxation
d. Exposure therapy
e. Flooding
f. Nitrous Oxide 


\section{Appendix G}

\section{Stimuli Order Presentation Preference Ranking}

Please rank the following ways you prefer to use the videos that you watch in order to treat your dental fear/anxiety:
a. Low intensity exposure
b. High intensity exposure
c. Low intensity then high intensity
d. High intensity then low intensity
e. Random order of low and high intensity 
Appendix $\mathrm{H}$

Treatment Effectiveness

1. How effective would you consider the LOW intensity exposure videos would be in treating your dental fear/anxiety?

Ineffective

0

2

3

Effective

4

2. How effective would you consider the HIGH intensity exposure videos would be in treating your dental fear/anxiety?

Ineffective

0

2

3

Effective

4 


\section{Appendix I}

Willingness to Engage in Treatment

1. How willing would you be to engage in LOW intensity exposure to treat your dental fear/anxiety?
Unwilling
0
1
2
3
Willing
4

2. How effective would you consider the HIGH intensity exposure videos would be in treating your dental fear/anxiety?
Unwilling
0
1
2
3
Willing
4 


\section{Appendix $\mathbf{J}$}

\section{Validity Check Question}

1. What color are healthy teeth?
a. Red
b. Green
c. White
d. Black

2. Please select the number four for this question
a. 1
b. 2
c. 3
d. 4
e. 5

3a*. What color outfit was the dental hygienist wearing?
a. Red
b. Black
c. White
d. Yellow
e. Green

$3 b^{\wedge}$. Was the patient wearing glasses in the video?
a. Yes
b. No

$4 a^{*}$. How many people were present most of the time in the video?
a. 1
b. 2
c. 3
d. 4

$4 b^{\wedge}$. The patient in the video...
a. Was clean shaven
b. Had a mustache
c. Had a goatee
d. Had a full beard

$5 \mathrm{a}^{*}$. The patient was a
a. Male
b. Female 
$5 b^{\wedge}$. What procedure took place in the video?
a. Tooth extraction
b. Shots to numb the mouth
c. Drilling tooth to fill a cavity
d. Teeth polishing

Note. *represents questions presented after viewing the low intensity video. ${ }^{\wedge}$ represents questions presented after viewing the high intensity video. 